\title{
A global off-line model of size-resolved aerosol microphysics: I. Model development and prediction of aerosol properties
}

\author{
D. V. Spracklen, K. J. Pringle, K. S. Carslaw, M. P. Chipperfield, and G. W. Mann \\ Institute for Atmospheric Science, School of Earth and Environment, University of Leeds, UK \\ Received: 2 November 2004 - Published in Atmos. Chem. Phys. Discuss.: 14 January 2005 \\ Revised: 8 June 2005 - Accepted: 6 July 2005 - Published: 19 August 2005
}

\begin{abstract}
A GLObal Model of Aerosol Processes (GLOMAP) has been developed as an extension to the TOMCAT 3-D Eulerian off-line chemical transport model. GLOMAP simulates the evolution of the global aerosol size distribution using a sectional two-moment scheme and includes the processes of aerosol nucleation, condensation, growth, coagulation, wet and dry deposition and cloud processing. We describe the results of a global simulation of sulfuric acid and sea spray aerosol. The model captures features of the aerosol size distribution that are well established from observations in the marine boundary layer and free troposphere. Modelled condensation nuclei $(\mathrm{CN}>3 \mathrm{~nm})$ vary between about $250-500 \mathrm{~cm}^{-3}$ in remote marine boundary layer regions and are generally in good agreement with observations. Modelled continental CN concentrations are lower than observed, which may be due to lack of some primary aerosol sources or the neglect of nucleation mechanisms other than binary homogeneous nucleation of sulfuric acidwater particles. Remote marine CN concentrations increase to around $2000-10000 \mathrm{~cm}^{-3}$ (at standard temperature and pressure) in the upper troposphere, which agrees with typical observed vertical profiles. Cloud condensation nuclei (CCN) at $0.2 \%$ supersaturation vary between about $1000 \mathrm{~cm}^{-3}$ in polluted regions and between 10 and $500 \mathrm{~cm}^{-3}$ in the remote marine boundary layer. New particle formation through sulfuric acid-water binary nucleation occurs predominantly in the upper troposphere, but the model results show that these particles contribute greatly to aerosol concentrations in the marine boundary layer. For this sulfur-sea salt system it is estimated that sea spray emissions account for only $\sim 10 \%$ of $\mathrm{CCN}$ in the tropical marine boundary layer, but between 20 and $75 \%$ in the mid-latitude Southern Ocean. In a run with only natural sulfate and sea salt emissions the global mean surface $\mathrm{CN}$ concentration is more than $60 \%$ of that from a run
\end{abstract}

Correspondence to: D. V. Spracklen

(dominick@env.leeds.ac.uk) with 1985 anthropogenic sulfur emissions, although the natural emissions comprise only $27 \%$ of total sulfur emissions. Southern hemisphere marine boundary layer $\mathrm{CN}$ are more than $90 \%$ natural in origin, while polluted continental $\mathrm{CN}$ are more than $90 \%$ anthropogenic in origin, although these numbers will change when other anthropogenic $\mathrm{CN}$ sources are included in the model.

\section{Introduction}

Particles in the atmosphere contribute to radiative forcing directly by scattering and absorbing radiation, and indirectly by altering the properties of clouds. The Intergovernmental Panel on Climate Change report (Houghton et al., 2001) estimated the direct forcing of anthropogenic aerosols to be $-0.5 \mathrm{~W} \mathrm{~m}^{-2}$ and the indirect forcing to lie between 0 and $-2 \mathrm{~W} \mathrm{~m}^{-2}$. These forcings are comparable, but opposite in sign, to the forcing of anthropogenic greenhouse gases.

The effect of changes in aerosol properties on clouds is a particularly uncertain quantity in climate simulations and also presents the greatest modelling challenge because of the many factors that control the links between aerosol properties and cloud properties. The most fundamental, though by no means only, quantity that needs to be accurately prognosed in a model is the concentration of cloud condensation nuclei $(\mathrm{CCN})$ - the subset of the aerosol, usually the largest particles, that can form cloud droplets at a particular supersaturation. The $\mathrm{CCN}$ number depends on the concentration and composition of particles greater than about $50 \mathrm{~nm}$ dry diameter, which is a size range that is influenced by primary particle production and by secondary particles that have grown to this size through condensation and coagulation processes on the timescale of days to weeks. The response of CCN concentrations to changes in the emissions of primary particles and precursor gases is therefore likely to be complex. 
In order to make a better estimate of the indirect effect it is important to understand the factors that control the number of $\mathrm{CCN}$ at a given supersaturation in a cloud. However, early global aerosol models were not able to simulate the particle size distribution and only predicted the mass of certain particle classes, such as sulfate (e.g., Langner and Rodhe, 1991; Kiehl and Briegleb, 1993; Pham et al., 1995; Boucher and Anderson, 1995; Chin et al., 1996; Feichter et al., 1996; Chuang et al., 1997; Feichter et al., 1997; Kasibhatla et al., 1997; Lelieveld et al., 1997; Kjellstrom, 1998; Restad et al., 1998; Roelofs et al., 1998; Koch et al., 1999; Kiehl et al., 2000; Barth et al., 2000; Rasch et al., 2000; Chin et al., 2000) or carbonaceous material (e.g., Cooke and Wilson, 1996; Kanakidou et al., 2000; Tegen et al., 2000; Chung and Seinfeld, 2002). Early climate simulations either relied on empirical relationships between aerosol mass and CCN concentration (e.g., Boucher and Lohmann, 1995; Jones et al., 1994, 2001; Menon et al., 2002), mechanistic schemes (e.g., Chuang et al., 2002), or used a physically-based parameterisation (Abdul-Razzak and Ghan, 2002; Nenes and Seinfeld, 2003). Although such empirically based schemes are computationally efficient for long climate change simulations and exploit the aerosol information in most climate models, they do not capture the dependence of cloud droplet concentration on aerosol properties that has been observed globally (Ramanathan et al., 2001).

More recently, large-scale models have been developed that are capable of a size-resolved description of aerosol distributions. The aerosol distribution has been modelled using a modal approach (see Whitby and McMurry, 1997) which uses the method of moments to solve the aerosol dynamical equations (ADEs) assuming the aerosol consists of a number of distinct sub-populations (modes), each of which has a size distribution given by a particular mathematical function (usually log-normal). The modal method has been used in a number of aerosol models (Schulz et al., 1998; Wilson et al., 2001; Ghan et al., 2001; Binkowski and Rosell, 2003; Vignati et al., 2004; Easter et al., 2004). Such schemes have the advantage of relative computational efficiency while retaining the principal features of the natural aerosol size distribution. A variation on this approach is the quadrature method of moments (McGraw, 1997) which does not make any assumption about the functional form of the aerosol size distribution, instead solving for the moments of the distribution using a Gaussian quadrature approximation to the integral growth term in the ADEs (Wright et al., 2000; Wright and Kasibhatla, 2001; Wright et al., 2002; Yu et al., 2003; McGraw and Wright, 2003). An alternative approach is to describe the size distribution in terms of discrete size sections (Tegen and Fung, 1994; Gong et al., 1997; Jacobson, 2001a; von Salzen et al., 2000; Jacobson, 2001b; Adams and Seinfeld, 2002; Gong et al., 2003). The sectional approach is relatively computationally expensive because at least 20 size sections are needed to represent the distribution. However, such schemes make no assumptions about the shape of the distribution, so offer a flexible and realistic way of describing highly variable natural distributions.

Early sectional schemes used a single-moment sectional method (von Salzen et al., 2000) in which the particle number in each size section is simulated. Later sectional schemes used a two-moment sectional method in which the mass per particle in each section is also simulated. Adams and Seinfeld (2002) incorporate the two-moment sectional scheme (TOMAS) into the GISS GCM for a description of sulfate aerosol and Gong et al. (2003) incorporate the two-moment sectional CAM module into the third generation Canadian GCMIII for a description of sulfate and sea salt aerosol (Gong and Barrie, 2003). Single-moment sectional methods suffer from the disadvantage that particle growth must be represented in terms of changes in particle number in each size section and may therefore not conserve total particle number. In GLOMAP we use a two-moment sectional method, as described in Sect. 2.

Development of size-resolved models of aerosol concentration brings with it the need to include the microphysical processes such as nucleation, condensation, coagulation and cloud processing that affect the size distribution. Although the global simulation of a fully size-resolved multicomponent aerosol is currently too numerically demanding for centennial scale climate model simulations, these models are essential tools for understanding what controls the microphysical - and ultimately the radiative and cloud-nucleating properties of the global aerosol. As we show here, the evolution of the size distribution and the factors that control $\mathrm{CCN}$ can be examined on timescales as short as 1 month, which is approximately the lifetime of the global tropospheric aerosol.

This paper is the first of three papers describing a new GLObal Model of Aerosol Processes (GLOMAP). This first paper describes the model and the global simulations of aerosol properties, including a basic level of model evaluation. The second paper (Spracklen et al., 2005) examines in detail the sensitivity of the predicted aerosol size distribution to uncertainties in the driving microphysical processes. The third paper, in preparation, will present a detailed comparison of the model against aerosol observations. The GLOMAP model described here is currently restricted to sea spray and sulfate aerosol.

Section 2 gives a description of the model. Section 3 describes the simulated global fields of sulfur species. Section 4 describes the simulated global aerosol properties.

\section{Model Description}

\subsection{The TOMCAT chemical transport model}

GLOMAP is an extension to the 3-D off-line Eulerian chemical transport model, TOMCAT, which is described in e.g. Stockwell and Chipperfield (1999). TOMCAT is forced by meteorological analyses and can be run at a range of 
resolutions and with different options for physical and chemical parametrisations. These options include a a comprehensive tropospheric chemistry scheme.

\subsubsection{Meteorology}

The model domain is global and the resolution used here is $2.8^{\circ} \times 2.8^{\circ}$ latitude $\times$ longitude with 31 hybrid $\sigma$-p levels extending from the surface to $10 \mathrm{hPa}$. The vertical geometric resolution varies from $60 \mathrm{~m}$ within the planetary boundary layer to $1 \mathrm{~km}$ at the tropopause. In the experiments performed here large-scale atmospheric transport is specified from European Centre for Medium-Range Weather Forecasts (ECMWF) analyses at 6-hourly intervals. Tracer advection is performed using the Prather advection scheme (Prather, 1986), which conserves second-order moments of the tracer field. The non-local vertical diffusion scheme of Holtslag and Boville (1993) calculates the planetary boundary layer height and eddy diffusion coefficients and is capable of representing convective turbulence. Sub-grid scale moist convection is parametrised using the scheme of Tiedtke (1989). Precipitation occurs due to sub-grid convective processes (also following Tiedtke (1989)) and due to frontal (or large scale) processes according to the scheme of Giannakopoulos et al. (1999).

\subsubsection{Gas phase chemistry and emissions}

The chemical reactions included in the model are listed in Table 1. Concentrations of $\mathrm{OH}, \mathrm{NO}_{3}, \mathrm{H}_{2} \mathrm{O}_{2}$ and $\mathrm{HO}_{2}$ are specified using 6-hourly monthly mean 3-D concentration fields from a TOMCAT run with detailed tropospheric chemistry and linearly interpolated onto the model timestep. The chemical scheme in Table 1 is considered the minimum necessary to examine the sulfur cycle and sulfate aerosol formation. Time-dependent chemical rate equations are solved using the IMPACT algorithm of the ASAD software package (Carver et al., 1997).

GLOMAP includes $\mathrm{SO}_{2}$ emissions from anthropogenic and volcanic sources and dimethyl sulfide (DMS) emissions from the ocean. Anthropogenic emissions are taken from the Global Emissions Inventory Activity (GEIA) database (Benkovitz et al., 1996), which are seasonally averaged and based on the year 1985. In the baseline model runs presented here all the emitted sulfur is assumed to be $\mathrm{SO}_{2}$, but in Spracklen et al. (2005) we also explore the sensitivity of modelled aerosol to small amounts of primary sulfate aerosol. The emissions inventory classifies emissions as occurring above or below $100 \mathrm{~m}$. The emissions are partitioned linearly onto the appropriate model grid levels according to the thickness of the model levels.

Oceanic DMS emissions are calculated using the monthly mean seawater DMS concentration database of Kettle et al. (1999) and the sea-to-air transfer velocity of Liss and Merlivat (1986). The wind speed at $10 \mathrm{~m}$, which is needed for
Table 1. Sulfur gas phase chemical reactions included in GLOMAP.

\begin{tabular}{ll}
\hline Reactions & Reference \\
\hline $\mathrm{DMS}+\mathrm{OH} \rightarrow \mathrm{SO}_{2}$ & Atkinson et al. (1989) \\
$\mathrm{DMS}+\mathrm{OH} \rightarrow 0.6 \mathrm{SO}_{2}+0.4 \mathrm{DMSO}$ & Pham et al. (1995) \\
DMSO+OH $\rightarrow 0.6 \mathrm{SO}_{2}+0.4 \mathrm{MSA}$ & Pham et al. (1995) \\
DMS $+\mathrm{NO}_{3} \rightarrow \mathrm{SO}_{2}$ & Atkinson et al. (1989) \\
$\mathrm{CS}_{2}+\mathrm{OH} \rightarrow \mathrm{SO}_{2}+\mathrm{COS}$ & Pham et al. (1995) \\
$\mathrm{COS}+\mathrm{OH} \rightarrow \mathrm{SO}_{2}$ & Pham et al. (1995) \\
$\mathrm{SO}_{2}+\mathrm{OH}+\mathrm{M} \rightarrow \mathrm{H}_{2} \mathrm{SO}_{4}$ & Pham et al. (1995) \\
\hline
\end{tabular}

the calculation of transfer velocity, is calculated from the ECMWF analyses used to force the model assuming a neutral surface layer and a roughness length of $0.001 \mathrm{~m}$ for the sea surface.

Volcanic emissions of $\mathrm{SO}_{2}$ are obtained from Andres and Kasgnoc (1998) and injected at a constant rate between pressure levels of 880 and $350 \mathrm{hPa}$ (Jones et al., 2001). Sporadically erupting volcanoes are not included in the model. All volcanic emissions are assumed to be $\mathrm{SO}_{2}$.

There are no emissions inventories for $\mathrm{COS}$ or $\mathrm{CS}_{2}$. Anthropogenic $\mathrm{COS}$ and $\mathrm{CS}_{2}$ are emitted at constant molar emission ratios of $\mathrm{SO}_{2}$ where $\mathrm{COS} / \mathrm{SO}_{2}=8 \times 10^{-4}$ and $\mathrm{CS}_{2} / \mathrm{SO}_{2}=3 \times 10^{-3}$ (Pham et al., 1995). Biogenic emissions of $\mathrm{COS}$ and $\mathrm{CS}_{2}$ are taken as constant molar emission ratios of DMS where $\mathrm{COS} / \mathrm{DMS}=1 \times 10^{-2}$ and $\mathrm{CS}_{2} / \mathrm{DMS}=1 \times 10^{-2}$ (Bates et al., 1992).

\subsection{The aerosol microphysics module}

\subsubsection{The aerosol size distribution}

The aerosol size distribution is simulated using the movingcentre scheme of Jacobson (1997a), which is often termed a two-moment sectional scheme. In this scheme the average mass per particle in each size section (or bin) as well as the total number concentration in the bin are carried (mass and number being the 2 moments). Within each section, the average particle size varies between the lower and upper bin edges as mass is added to, or removed from, the particles, for example due to condensation and evaporation. If the average particle mass in a bin exceeds its fixed bin edge the total mass and number of particles in this bin is added to the appropriate new bin (not necessarily the adjacent one). The number concentration of the original bin is set to zero and its average mass re-set to the mid-point mass. Such a two-moment scheme explicitly describes the growth of a size distribution in terms of changes in the mass of the particles in a bin. In contrast, in a single-moment number-only scheme growth must be described in terms of the change in the number of fixed-size particles in each bin. Two-moment schemes have the advantage of greatly reducing the numerical diffusion 
(in radius space) that is a characteristic of single-moment number-only schemes (Jacobson, 1997a; Korhonen et al., 2003), but have the disadvantage in a 3-D model that two pieces of information need to be carried to define the size distribution of a single-component aerosol. A multi-component, two-moment scheme results in a large increase in information needing to be carried. However, whilst the number of extra model tracers required to simulate the mass per particle in the two-moment scheme increases linearly with the number of chemical components in each particle only one number concentration is required for each distribution.

The bin centres are geometrically (mass ratio) spaced and span 0.001 to $25 \mu \mathrm{m}$ equivalent dry diameter. The number of bins can be set arbitrarily, although the number required to capture the principal features of the natural size distribution is about 20 (Gong et al., 2003), which we use here. Water is not included as an aerosol component. Instead, particles are allowed to re-equilibrate with the ambient relative humidity before calculating size-dependent quantities such as the coagulation kernel. The model conserves aerosol number and aerosol mass.

\subsubsection{Microphysical processes}

These simulations are restricted to sulfuric acid aerosol (formed through gas-to-particle conversion of gaseous $\mathrm{H}_{2} \mathrm{SO}_{4}$ ) and sea spray. As a further simplification, these two aerosol types are assumed to have the same physical properties (density and hygroscopic behaviour) and their chemical properties are not simulated (that is, we do not calculate the chemical composition and cation/anion speciation of the particles). The chemical equilibration of mixed electrolytes is a complex and numerically expensive problem to solve in a global model (Jacobson, 1997b) and the effects, in terms of particle size distribution, are likely to be subtle in most parts of the atmosphere.

The number of solute molecules per particle in each size bin is converted to a particle volume using the Köhler equation appropriate for sulfuric acid-water mixtures and relative humidities from the meteorological analyses. The assumption that the sea spray particles have the same hygroscopic properties as sulfuric acid will lead to a factor 1.33 difference in the diameter of the particles under humid oceanic conditions where most of the sea spray particles reside (Gong et al., 2003).

New particle formation is treated using the binary $\mathrm{H}_{2} \mathrm{SO}_{4}$ $\mathrm{H}_{2} \mathrm{O}$ nucleation scheme of Kulmala et al. (1998). This scheme is valid down to temperatures of $233 \mathrm{~K}$. Below this temperature we use the rate at $233 \mathrm{~K}$. New particles are assumed to nucleate at a size of 100 molecules of $\mathrm{H}_{2} \mathrm{SO}_{4}$ per particle.

Condensation of $\mathrm{H}_{2} \mathrm{SO}_{4}$ onto all particles is calculated using the modified Fuchs-Sutugin equation (Fuchs and Sutugin, 1971). The noncontinuum effect that occurs during condensation onto small particles is accounted for using a correction factor which is a function of the Knudsen number. The accommodation coefficient, $a_{e}$, is assumed to have a value of unity, although the sensitivity of the aerosol distribution to the magnitude of $a_{e}$ is explored in Spracklen et al. (2005).

Coagulation of particles is calculated using the mass conserving semi-implicit numerical solution of Jacobson et al. (1994). The coagulation kernels account only for Brownian diffusion, which is the dominant mechanism for submicron particles. Kernels are calculated using the size of the particles after equilibration with water.

Dry deposition of aerosols is based on the schemes of Slinn and Slinn (1981) and Zhang et al. (2001). It includes the deposition processes of gravitational settling, Brownian diffusion, impaction, interception and particle rebound. Deposition rates are dependent on particle size, land use category (e.g. forest, ocean etc) and wind speed.

In-cloud aqueous phase oxidation of $\mathrm{SO}_{2}$ to form aqueous $\mathrm{H}_{2} \mathrm{SO}_{4}$ is calculated in grid boxes that contain low stratiform cloud according to global fields from the International Satellite Cloud Climatology Project D1 database (Rossow and Schiffer, 1999). Precipitating, deep convective and frontal clouds are assumed to only remove sulfur gases by wet deposition. Formation of sulfate in convective clouds is limited by availability of S(IV) and oxidants (Laj et al., 1997). We assume that particles with a dry diameter larger than $0.05 \mu \mathrm{m}$ activate. The maximum rate of aqueous oxidation is set by the rate of diffusion of $\mathrm{SO}_{2}$ onto the activated particle distribution, which is calculated using the Fuchs-Sutugin equation (Fuchs and Sutugin, 1971). Available $\mathrm{SO}_{2}$ is reacted stoichiometrically with $\mathrm{H}_{2} \mathrm{O}_{2}$ and the concentrations of both are reduced accordingly. Sulfate is added to the particle distribution and partitioned between different size bins depending on the rates of $\mathrm{SO}_{2}$ diffusion to each particle size bin. If $\mathrm{H}_{2} \mathrm{O}_{2}$ concentrations were allowed to return to the prescribed values at the end of each time step this would cause an overprediction of $\mathrm{H}_{2} \mathrm{O}_{2}$ oxidation rates. Instead $\mathrm{H}_{2} \mathrm{O}_{2}$ is replenished using the prescribed concentration of $\mathrm{HO}_{2}$ (Jones et al., 2001).

The emission of sea spray particles is calculated using the parametrisation of Gong (2003), which produces realistic emissions at particle sizes between 0.07 and $20 \mu \mathrm{m}$ at $80 \%$ humidity (corresponding to approximately 0.035 and $10 \mu \mathrm{m}$ dry diameter). This parametrisation is an extension of the semi-empirical formulation of Monahan et al. (1986) to below $0.2 \mu \mathrm{m}$ diameter, where the original parametrisation was found to overestimate emissions of sub-micron sea spray particles. The adjustable parameter $(\Theta)$ that controls sub-micron emissions is set at 30 .

GLOMAP includes descriptions of both in-cloud and below-cloud aerosol wet deposition (due to both convective and frontal precipitation). The in-cloud (or nucleation) scavenging scheme assumes a removal rate of activated aerosol that is proportional to the amount of condensate converted to rain in each timestep. Below-cloud scavenging (impaction 
by raindrops) is parameterised following Slinn (1983) with scavenging coefficients taken from Beard and Grover (1974). The raindrop distribution is assumed to follow the MarshallPalmer distribution (with the sophistication of Sekhon and Srivastava (1971)) and is described with seven geometrically spaced raindrop bins.

\subsubsection{Numerical treatment}

The differential equations that govern the particle mass and number concentration in each size section are solved using operator splitting. This technique has been widely used in large-scale atmospheric models and has the advantage of being considerably cheaper in CPU usage compared to the fully coupled solution. The accuracy of the operator splitting depends on the length of the timestep used. A flowchart of the microphysical operations in GLOMAP is shown in Fig. 1. The TOMCAT model timestep is split into a number of shorter subtimesteps that account for the time scales on which the different microphysical processes operate. The advection timestep is usually $1800 \mathrm{~s}$. This is split into NCTS timesteps (normally 2) over which the emissions and chemistry are solved. This timestep is then further split into NMTS timesteps (normally 2) over which the aerosol microphysics is solved. To accurately represent the competition between nucleation and condensation processes this microphysics timestep is subdivided further into NNTS timesteps (normally 5) where condensation and nucleation are calculated.

The accuracy of operator splitting has been tested by changing the length of the different timesteps and the order of operations. Changing the order of operations or further reducing the timestep length changes total aerosol number concentrations by less than $5 \%$.

\subsection{Model experiments}

The runs were forced by ECMWF analyses. The model runs shown here are for December 1995 and July 1997. The model was spun up from an aerosol-free atmosphere (on 1 October 1995 and 1 May 1997) for a period of 60 days before model output was used. This length of time is sufficient so that model simulations are independent of the model initialisation fields.

\section{Global sulfur species}

Table 2 shows the GLOMAP sulfur budget compared to previous published global models. In GLOMAP sulfate and seasalt are treated within the same particle distribution and it is not possible to distinguish between the two components. Therefore, we cannot compare GLOMAP sulfate with earlier models. GLOMAP and Adams and Seinfeld (2002) are the only models to prognose gas-phase $\mathrm{H}_{2} \mathrm{SO}_{4}$.

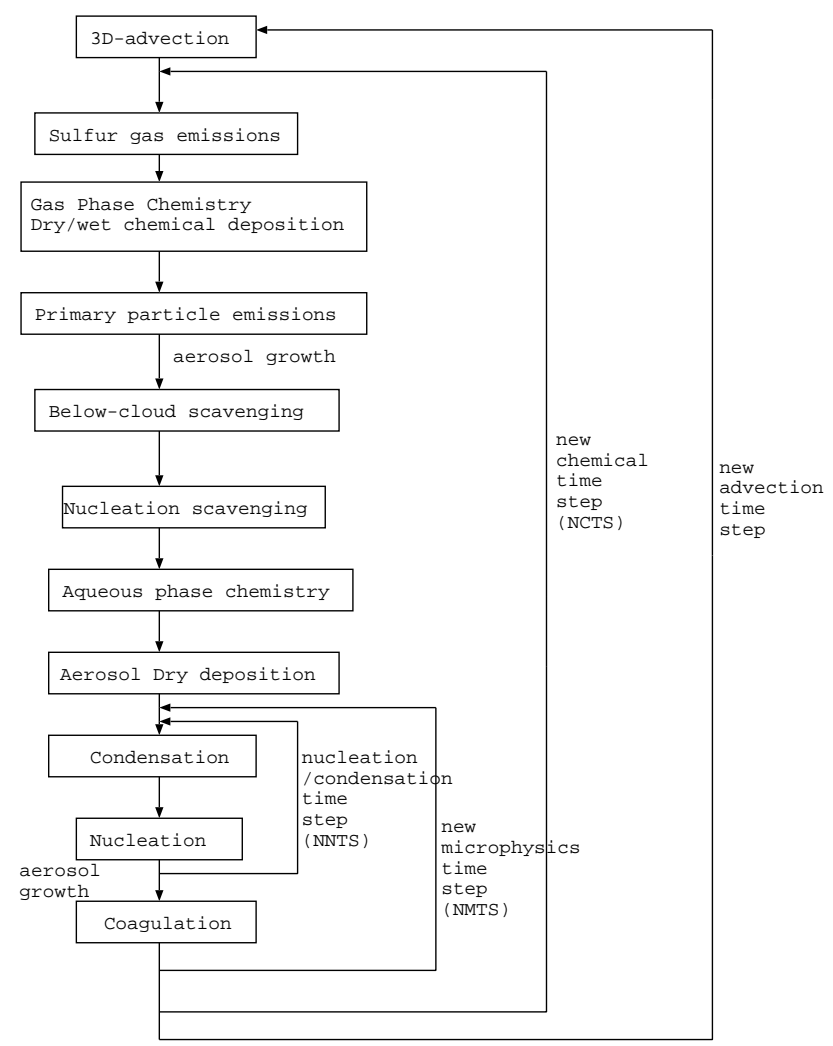

Fig. 1. The flowchart of processes in GLOMAP.

Emissions of DMS and $\mathrm{SO}_{2}$ in GLOMAP are within the range published by earlier studies. GLOMAP uses the same DMS sea-surface concentration and calculation of transfer velocity as Chin et al. (2000) and Koch et al. (1999) but has higher global DMS emissions due to different model wind speeds. GLOMAP DMS lifetime and burden is at the lower end of the estimates made by other models. This may be due to different $\mathrm{OH}$ distributions and/or different spatial distribution of DMS emissions. Global annual mean TOMCAT OH concentrations are $0.8 \times 10^{6} \mathrm{~cm}^{-3}$ in the NH and $0.7 \times 10^{6} \mathrm{~cm}^{-3}$ in the $\mathrm{SH}$, which compare well with observed values of $0.9 \times 10^{6} \mathrm{~cm}^{-3}$ and $0.99 \times 10^{6} \mathrm{~cm}^{-3}$ in the $\mathrm{NH}$ and SH, respectively (Prinn et al., 2001). MSA lifetime in GLOMAP is longer then in other models by a factor of 2-3. This is due to the lack of MSA wet deposition in GLOMAP which in other models is the dominant sink. MSA is not used by GLOMAP for calculation of aerosol properties (there is no condensation of MSA onto existing aerosol) and so concentrations are not important for simulation of aerosol properties. $\mathrm{SO}_{2}$ lifetime and burden is highest in the GISS model (Koch et al., 1999; Adams and Seinfeld, 2002) which has been explained by their model prognosing $\mathrm{H}_{2} \mathrm{O}_{2}$.

Figure 2 shows zonal, 1996 average DMS and $\mathrm{SO}_{2}$. Simulated $\mathrm{SO}_{2}$ concentrations are highest in the $\mathrm{NH}$ between about $30-60^{\circ} \mathrm{N}$. GLOMAP $\mathrm{SO}_{2}$ concentrations in the $\mathrm{NH}$ free troposphere are very similar to those of 
Table 2. Comparison of the sulfur budget in GLOMAP (G05) with previous sulfur models.

\begin{tabular}{|c|c|c|c|c|c|c|c|c|c|c|c|c|c|c|}
\hline & LR91 & P95 & C96 & F96 & C97 & L97 & R00 & K99 & $\mathrm{C} 00$ & ASO2 & IS02 & E04 & B04 & G05 \\
\hline \multicolumn{15}{|c|}{ S emissions, $\mathrm{Tg} \mathrm{S} / \mathrm{yr}$} \\
\hline DMS & 16.0 & 20.0 & 21.8 & 16.9 & 23.7 & 16.0 & 15.5 & 10.7 & 13.3 & 10.8 & 26.0 & 19.2 & 12.0 & 18.7 \\
\hline Total & 98.0 & 124.6 & 96.7 & 100.7 & 106.0 & 94.0 & 83.0 & 83.0 & 93.9 & 83.6 & 99.9 & 89.6 & 89.2 & 90.8 \\
\hline \multicolumn{15}{|l|}{$\mathrm{SO}_{2}$ sinks, $\mathrm{Tg} \mathrm{S} / \mathrm{yr}$} \\
\hline Dry deposition & 30.5 & 55.0 & 26.6 & 40.2 & 38.7 & & 24.5 & 35.5 & 41.2 & 37.9 & & 23.0 & 41.3 & 36.0 \\
\hline Wet deposition & 14.2 & 5.8 & 19.9 & 9.0 & 18.9 & & 1.6 & 0.2 & 10.6 & 1.5 & & 7.1 & 1.5 & 9.8 \\
\hline Total & 94.5 & 122.8 & 95.6 & 100.5 & 106.0 & & 79.7 & 80.4 & 90.3 & 82.6 & & 86.2 & 89.2 & 90.9 \\
\hline \multicolumn{15}{|c|}{$\mathrm{H}_{2} \mathrm{SO}_{4}$ sinks, $\mathrm{Tg} \mathrm{S} / \mathrm{yr}$} \\
\hline \multicolumn{15}{|l|}{ Burden / Tg S } \\
\hline $\mathrm{SO}_{2}$ & 0.3 & 0.2 & 0.34 & 0.43 & 0.36 & 0.6 & 0.4 & 0.56 & 0.43 & 0.68 & 0.37 & 0.44 & 0.26 & 0.49 \\
\hline DMS & 0.13 & 0.05 & 0.06 & 0.1 & & 0.02 & 0.06 & 0.06 & 0.07 & 0.05 & 0.1 & 0.15 & & 0.04 \\
\hline MSA & & 0.02 & 0.02 & & & & & 0.02 & 0.03 & 0.02 & & 0.03 & & 0.02 \\
\hline \multicolumn{15}{|l|}{ Lifetime / days } \\
\hline $\mathrm{SO}_{2}$ & 1.2 & 0.6 & 1.3 & 1.5 & 1.3 & 5.3 & 1.9 & 2.6 & 1.8 & 3.0 & 1.5 & 1.8 & 1.06 & 2.0 \\
\hline DMS & 3.0 & 0.9 & 1.0 & 2.2 & & 0.5 & 1.4 & 1.9 & 2.0 & 1.7 & 1.4 & 2.8 & & 0.8 \\
\hline MSA & & 6.1 & 6.2 & & & & & 7.6 & 7.1 & 7.5 & & 5.6 & & 18.5 \\
\hline
\end{tabular}

LR91 Langner and Rodhe (1991), P95 Pham et al. (1995), C96 Chin et al. (1996), F96 Feichter et al. (1997), C97 Chuang et al. (1997), L97 Lelieveld et al. (1997), R00 Rasch et al. (2000) and Barth et al. (2000), K99 Koch et al. (1999), C00 Chin et al. (2000), AS02 Adams and Seinfeld (2002), IS02 Iversen and Seland (2002), EO4 Easter et al. (2004), B04 Berglen et al. (2004), G05 this work, simulation is for 1996.
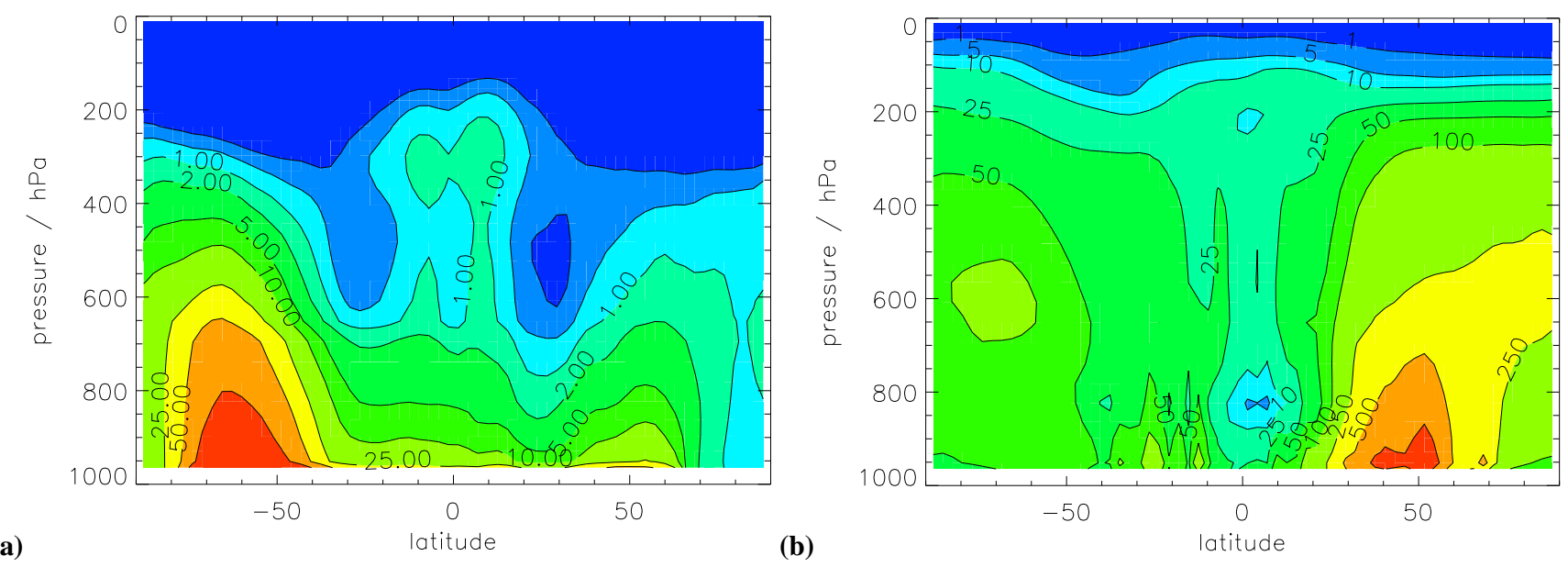

Fig. 2. Simulated zonal 1996 average concentrations (pptv) for (a) DMS and (b) $\mathrm{SO}_{2}$.

Koch et al. (1999) and Chin et al. (2000) but about double those simulated by Feichter et al. (1996). This may be caused by the way the models treat in-cloud oxidation. Models that use off-line $\mathrm{H}_{2} \mathrm{O}_{2}$ and allow concentrations to 

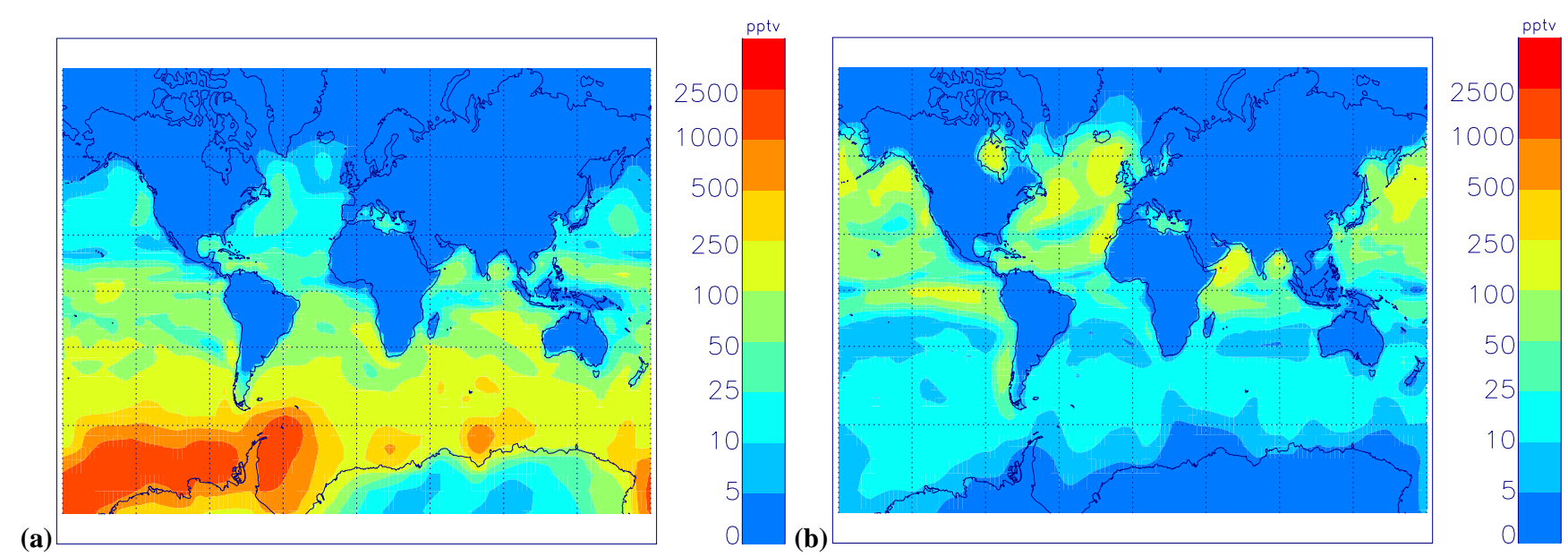

Fig. 3. Simulated monthly mean surface DMS concentrations (in pptv) during (a) December 1995 and (b) July 1997.

regenerate immediately to the prescribed values will overestimate in-cloud oxidation. GLOMAP simulates an assymetric zonal distribution of DMS between the northern and southern hemispheres similar to Barth et al. (2000), whereas other models (Koch et al., 1999; Chin et al., 2000) simulate a symmetric distribution between the hemispheres. This is caused by different spatial emissions of DMS and different distributions of $\mathrm{OH}$ which will effect DMS lifetime and FT concentrations.

Figure 3 shows simulated surface level DMS concentrations. DMS concentrations are highest over oceanic areas (between 5 and 2000 pptv) due to oceanic DMS emissions, and very low over terrestrial areas (less than 5 pptv). The model does not include any terrestrial emissions of DMS and so will tend to underpredict DMS concentrations over land. However, continental emissions of DMS are small and this should not be significant (Pham et al., 1995). The lifetime of DMS is approximately 1 day so its distribution is strongly governed by its sources, and atmospheric DMS concentrations in the marine boundary layer (MBL) closely follow the DMS concentrations in seawater. The simulations show the strong seasonal variability in atmospheric DMS concentrations caused by the cycle in biological activity altering sea surface DMS concentrations.

The largest simulated DMS concentrations occur over the tropical oceans and in the $30-60^{\circ}$ oceanic belt of the summer hemisphere. This distribution reflects larger DMS emissions in these regions, due to a combination of high ocean surface DMS concentrations and higher wind speeds at the higher latitudes. Maximum values above the equatorial oceans of 300 pptv, and at high SH latitudes during the summer of over 1000 pptv, are calculated. Low DMS sea-surface concentrations in the winter hemisphere cause low DMS emissions and low winter hemisphere atmospheric concentrations. Coastal areas with strong oceanic upwelling (e.g., the Peru upwelling zone) have elevated DMS sea surface concentrations (Kettle et al., 1999) leading to higher atmospheric concentrations.
Figure 4 shows simulated surface level $\mathrm{SO}_{2}$ concentrations. Concentrations of $\mathrm{SO}_{2}$ are high over the United States, Europe and the Far East where there are large emissions from fossil fuel burning. Additional maxima are observed over certain locations in Siberia and in the SH in Africa and South America due to smelting activities. The lifetime of $\mathrm{SO}_{2}$ is sufficiently long that transport of $\mathrm{SO}_{2}$ away from these source regions is apparent, particularly from the east coast of the United States and the east coast of Asia. In December the model simulates strong advection of $\mathrm{SO}_{2}$ from Europe and the United States to regions north of the Arctic circle. The aerosol mass loading is also greatly increased in Arctic regions affected by such transport of anthropogenic $\mathrm{SO}_{2}$ (see Sect. 4).

The model captures the observed (e.g., Rasch et al., 2000) seasonal cycle of $\mathrm{SO}_{2}$ over the northern hemisphere $(\mathrm{NH})$, with wintertime concentrations being a factor of two higher than summertime concentrations. This cycle has been explained by higher emissions (over Europe winter emissions in the GEIA inventory are about $30 \%$ higher than in summer), lower oxidant concentrations, and a stable boundary layer during winter months (Rasch et al., 2000). In clean marine areas $\mathrm{SO}_{2}$ concentrations of between 10 and $100 \mathrm{ppt}$ are simulated, with the majority of the $\mathrm{SO}_{2}$ deriving from DMS oxidation. Concentrations of $\mathrm{SO}_{2}$ in the $\mathrm{SH}$ winter are very low due to low concentrations of DMS. The low concentrations of around $10 \mathrm{ppt}$ in the tropics are due to efficient aqueous phase oxidation and removal in clouds.

Table 3 shows a comparison of GLOMAP annual average DMS and $\mathrm{SO}_{2}$ concentrations with observations. Model values are those of the nearest grid point to the observation. European data from the Evaluation of the Long Range Transmission of Air Pollutants in Europe (EMEP) (Schaug et al., 1987) is the average for the years 1980-1990. GLOMAP uses $\mathrm{SO}_{2}$ emissions for the year 1985 and so comparison with observations during this period was seen as most comparable (Koch et al., 1999). 

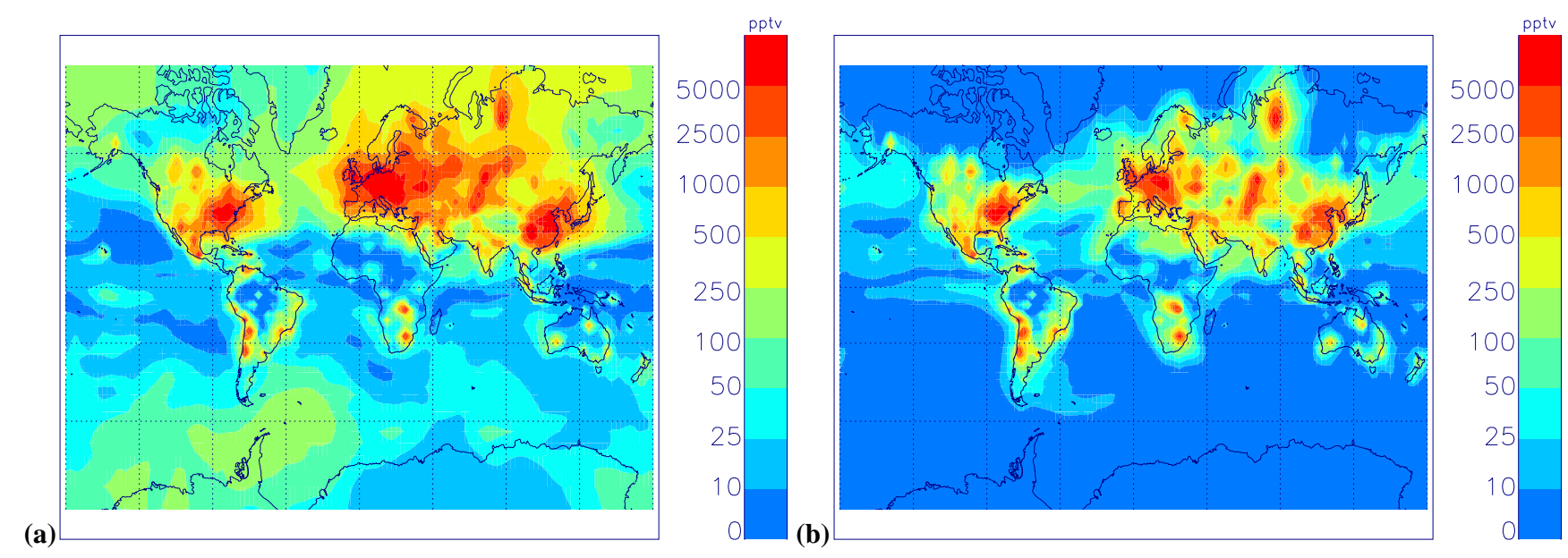

Fig. 4. As for Fig. 3 but for $\mathrm{SO}_{2}$.

Table 3. Annual mean observed and simulated $\mathrm{SO}_{2}$ and DMS concentrations in surface air.

\begin{tabular}{llll}
\hline Location & $\begin{array}{l}\text { Observed } \\
\text { /pptv }\end{array}$ & $\begin{array}{l}\text { Model } \\
\text { /pptv }\end{array}$ & Reference \\
\hline $\mathrm{SO}_{2}$ & & & \\
Langenburgge, Germany $\left(53^{\circ} \mathrm{N}, 11^{\circ} \mathrm{E}\right)$ & 7045 & 6023 & EMEP \\
Illmitz, Austria $\left(48^{\circ} \mathrm{N}, 17^{\circ} \mathrm{E}\right)$ & 7106 & 9979 & EMEP \\
Ispra, Italy $\left(46^{\circ} \mathrm{N}, 9^{\circ} \mathrm{E}\right)$ & 3262 & 4342 & EMEP \\
Mohican Forest, Ohio $\left(41^{\circ} \mathrm{N}, 82^{\circ} \mathrm{W}\right)$ & 7980 & 9531 & Shaw and Paur (1983) \\
Franklin County, Indiana $\left(40^{\circ} \mathrm{N}, 85^{\circ} \mathrm{W}\right)$ & 8530 & 5367 & Shaw and Paur (1983) \\
Union County, Kentucky $\left(38^{\circ} \mathrm{N}, 88^{\circ} \mathrm{W}\right)$ & 7520 & 8493 & Shaw and Paur (1983) \\
Cree Lake, Canada $\left(58^{\circ} \mathrm{N}, 107^{\circ} \mathrm{W}\right)$ & 242 & 107 & Barrie and Bottenheim (1990) \\
Spitzbergen, Norway $\left(79^{\circ} \mathrm{N}, 12^{\circ} \mathrm{E}\right)$ & 159 & 128 & EMEP \\
Bear Island, Norway $\left(75^{\circ} \mathrm{N}, 19^{\circ} \mathrm{E}\right)$ & 205 & 184 & Heintzenberg and Larssen (1983) \\
Jergul, Norway $\left(69^{\circ} \mathrm{N}, 25^{\circ} \mathrm{E}\right)$ & 779 & 425 & EMEP \\
Janiskoski, Russia $\left(69^{\circ} \mathrm{N}, 29^{\circ} \mathrm{E}\right)$ & 695 & 1026 & EMEP \\
Athäri, Finland $\left(62^{\circ} \mathrm{N}, 29^{\circ} \mathrm{E}\right)$ & 1831 & 1776 & EMEP \\
Amsterdam Island $\left(38^{\circ} \mathrm{N}, 24^{\circ} \mathrm{E}\right)$ & 19 & 27 & Nguyen et al. (1992) \\
& & & \\
DMS & & & \\
Amsterdam Island $\left(38^{\circ} \mathrm{N}, 78^{\circ} \mathrm{E}\right)$ & 112 & 80 & Nguyen et al. (1992) \\
Cape Grim (42 $\left.{ }^{\circ} \mathrm{N}, 145^{\circ} \mathrm{E}\right)$ & 67 & 73 & Ayers et al. (1991) \\
\hline
\end{tabular}

Over polluted regions the model reproduces annual mean $\mathrm{SO}_{2}$ concentrations to within $30 \%$ (except for Franklin County, Indiana). The model generally overestimates $\mathrm{SO}_{2}$ concentrations over polluted areas of Europe, which is typical of earlier models (Pham et al., 1995; Feichter et al., 1996; Roelofs et al., 1998; Koch et al., 1999). Insufficient transport out of the boundary layer and/or insufficient oxidation rates have been suggested as potential reasons for this. There are few long term observations of DMS which makes a rigorous comparison with measurements difficult. At two remote stations in the SH the simulated annual mean DMS concentrations agree with observations to within $40 \%$.
Figures 5 and 6 show a comparison of observed and simulated monthly mean DMS and $\mathrm{SO}_{2}$ concentrations. At Amsterdam Island, GLOMAP models the observed seasonal DMS cycle quite well except in January where the model underpredicts DMS. At Cape Grim modelled monthly mean concentrations are higher than observed (by as much as a factor of 4). Overprediction of DMS has been reported by other models (Chin et al., 1996; Barth et al., 2000) and may be due to uncertainty in the DMS flux, $\mathrm{OH}$ concentrations that are too low or an oxidation reaction not included in the model. The Southern Ocean is a region of high DMS sea surface concentrations and relatively sparse observations which 

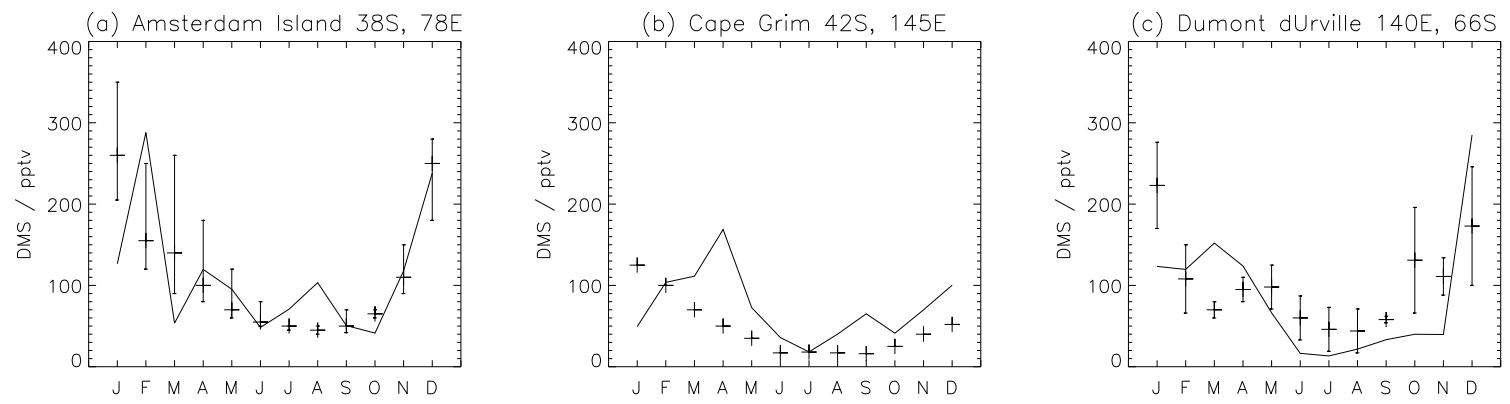

Fig. 5. Comparison of monthly mean observed (crosses) and simulated (solid line) surface DMS concentrations. Vertical lines show standard deviation of observed monthly values. Observations are from (a) Amsterdam Island January 1984-August 1984, March 1987-December 1990 (Nguyen et al., 1992), (b) Cape Grim, November 1988-December 1990, (Ayers et al., 1991) and (c) Dumont d'Urville, December 1998-July 1999 (Jourdain and Legrand, 2001).
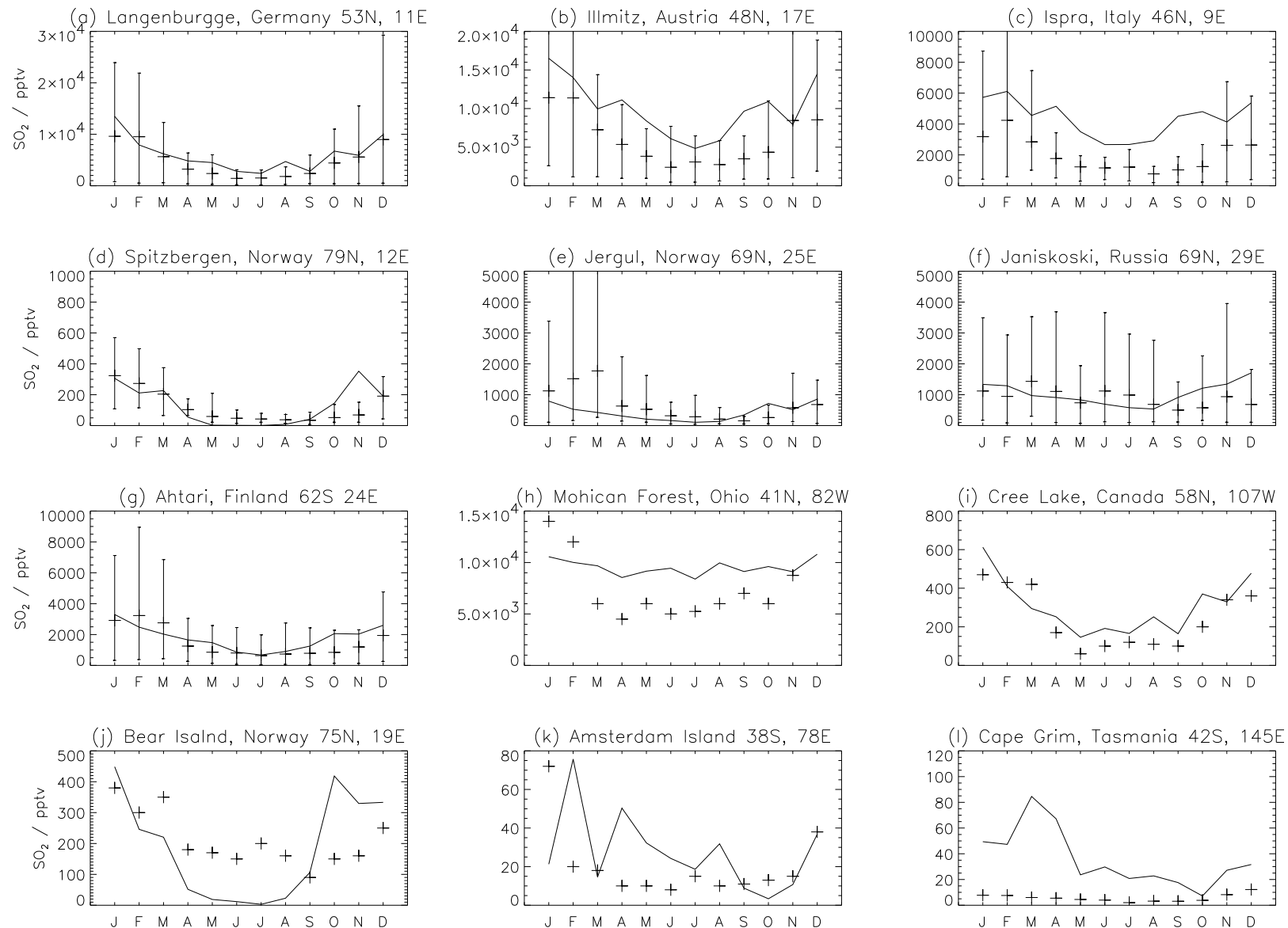

Fig. 6. Comparison of monthly mean GLOMAP simulated (line) and observed (crosses) $\mathrm{SO}_{2}$. Vertical lines show 5th and 95th percentiles of observed monthly values. (a-g) European data from EMEP, 1980-1990 monthly mean, (Schaug et al., 1987) (h) Ohio, USA, May 1980Aug 1981 (Shaw and Paur, 1983), (i) Cree Lake, Canada, 1982-1988 (Barrie and Bottenheim, 1990), (j) Bear Island, Norway, October 1978-September 1981 (Heintzenberg and Larssen, 1983), (k) Amsterdam Island, January 1984-August 1984, March 1987-December 1990 (Nguyen et al., 1992), (l) Cape Grim, November 1988-December 1990(Ayers et al., 1991).

results in a larger uncertainty when interpolating from the sea surface observations to the emissions grid (Kettle et al., 1999).
GLOMAP agrees well with $\mathrm{SO}_{2}$ observations in $\mathrm{NH}$ midlatitudes. In general, the model captures the annual cycle of $\mathrm{SO}_{2}$, with higher concentrations in the winter than in the 
(a) Christmas Island, 0-10N, 200-220E

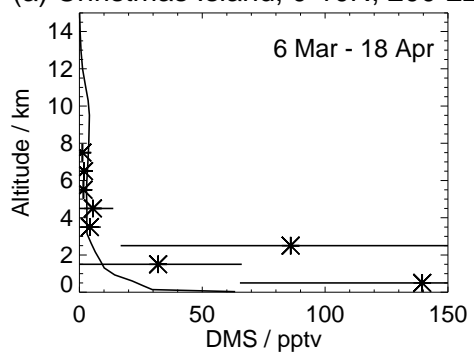

(d) Japan Coast, 20-40N, 130-150E

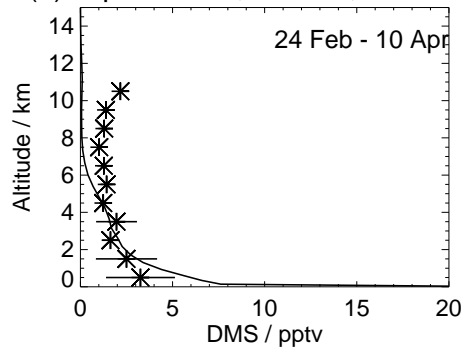

(g) Tahiti, 20S-0S, 200-230E

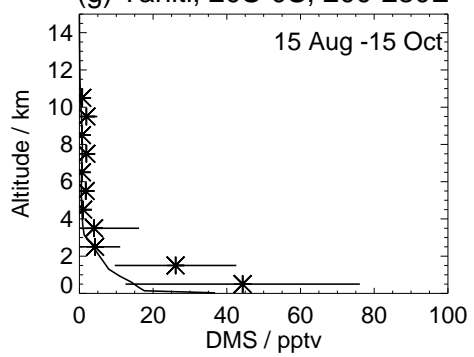

(b) Guam, $10-20 \mathrm{~N}, 140-150 \mathrm{E}$

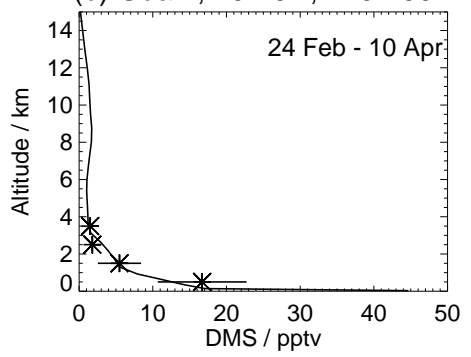

(e) Easter Island, 20-40S, 240-260E

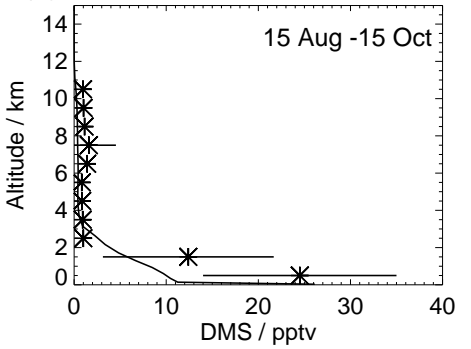

(h) Christmas Island, 0-10N, 200-200E

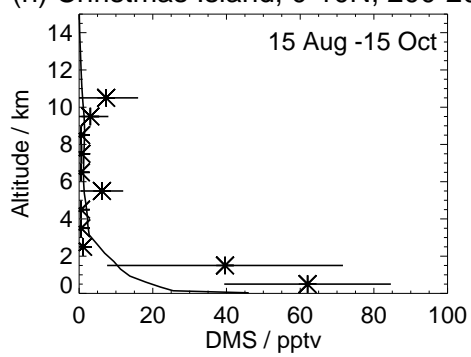

(c) China Coast, $10-30 \mathrm{~N}, 110-130 \mathrm{E}$
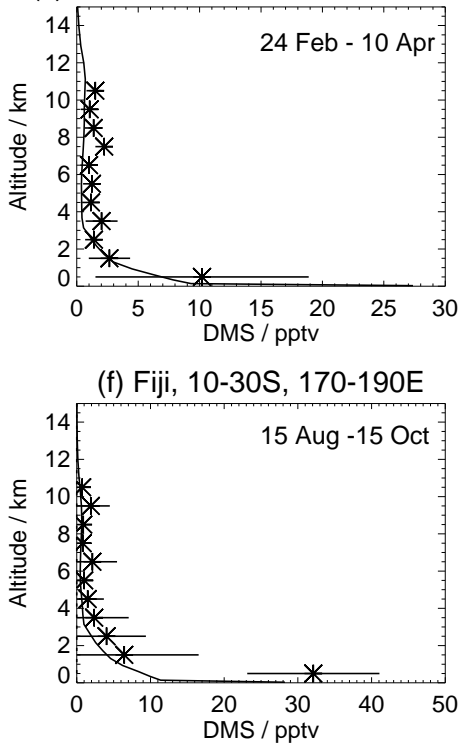

(i) Hawaii $10-30 \mathrm{~N}, 190-210 \mathrm{E}$

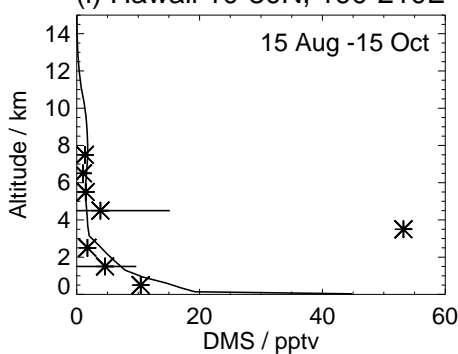

Fig. 7. Comparison of modelled (solid line) and observed (stars) vertical profiles of DMS. Error bars show \pm 1 standard deviation in the observations. Observations are from (a) PEM-Tropics B, (b-d) TRACE-P, (e-i) PEM-Tropics A (Emmons et al., 2000).

summer. The exception to this is at Mohican Forest, Ohio where the model simulates virtually no annual cycle causing an underprediction of $\mathrm{SO}_{2}$ during winter months and an overprediction during the summer. At this location, the annual cycle is captured quite well by other models (Chin et al., 1996; Barth et al., 2000) including those that prescribe $\mathrm{H}_{2} \mathrm{O}_{2}$. GLOMAP may have wintertime oxidant concentrations that are too high or dry deposition that is too effective. In-cloud oxidation is an important sink for $\mathrm{SO}_{2}$ and is treated differently by the different models. GLOMAP captures the observed arctic winter $\mathrm{SO}_{2}$ maximum (Fig. 6d, j) but tends to underpredict summertime values. Earlier models (Chin et al., 1996; Barth et al., 2000) tended to underpredict summertime concentrations and overpredict winter concentrations which was attributed to incorrect transport or deposition rates being inaccurate.

Vertical profiles of DMS and $\mathrm{SO}_{2}$ from PEM-Tropics A (September-October 1996) and PEM-Tropics B (MarchApril 1999) and from the TRACE-P (February-April 2001) missions were compared with GLOMAP monthly mean simulations for the same regions. Vertical profile data are com- posites of observations bined into altitude ranges (Emmons et al., 2000). The grid points of the model that lie within the boundaries of the measurement region were averaged to give the simulated profile. Figures 7 and 8 show comparison with DMS and $\mathrm{SO}_{2}$, respectively.

All the DMS observations are over the Pacific Ocean. The model generally captures the observed vertical profiles with high DMS concentrations near the surface and low DMS concentrations above the $\mathrm{BL}$. Simulated $\mathrm{SO}_{2}$ is generally in good agreement with observations. Over the China coast the model overestimates transport of $\mathrm{SO}_{2}$ from the $\mathrm{BL}$ to the lower FT. Over Fiji GLOMAP underestimates $\mathrm{SO}_{2}$ in the $\mathrm{BL}$. The high observed BL concentrations are probably due to local emissions which are not included in the model.

\section{Global aerosol properties}

\subsection{Global CN and CCN distributions}

Figure 9 shows GLOMAP surface monthly mean condensation nuclei $(\mathrm{CN})$ concentrations for July and December. To 
(a) North Atlantic, 32-40N, 280-290E

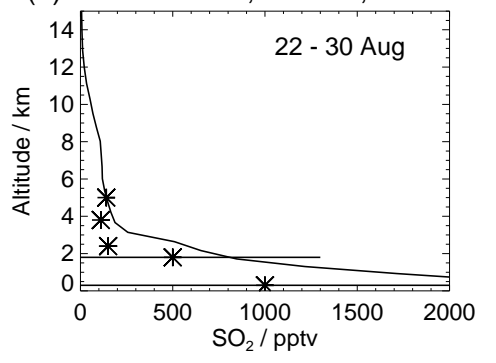

(d) Japan Coast, 20-40N, 130-150E

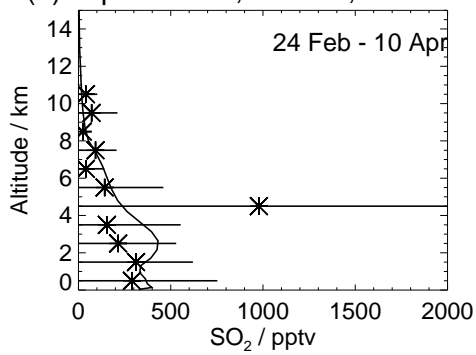

(g) Tahiti, 20S-0S, 200-230E

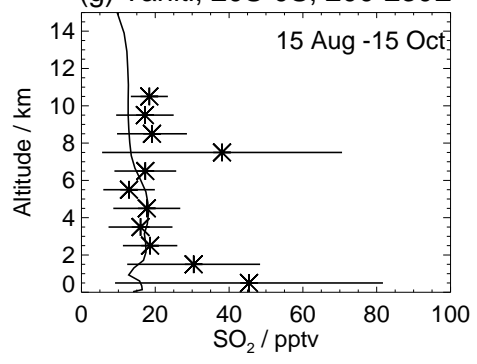

(b) S Atlantic, 40-45S, 140-150E

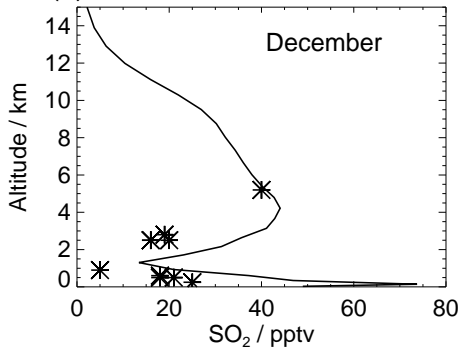

(e) Easter Island, 20-40S, 240-260E

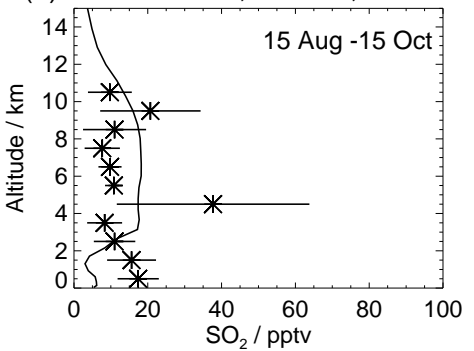

(h) Christmas Island, 0-10N, 200-200E

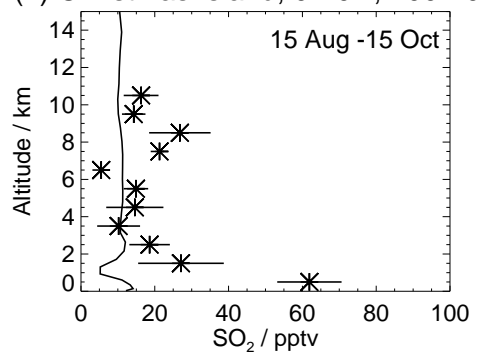

(c) China Coast, 10-30N, 110-130E
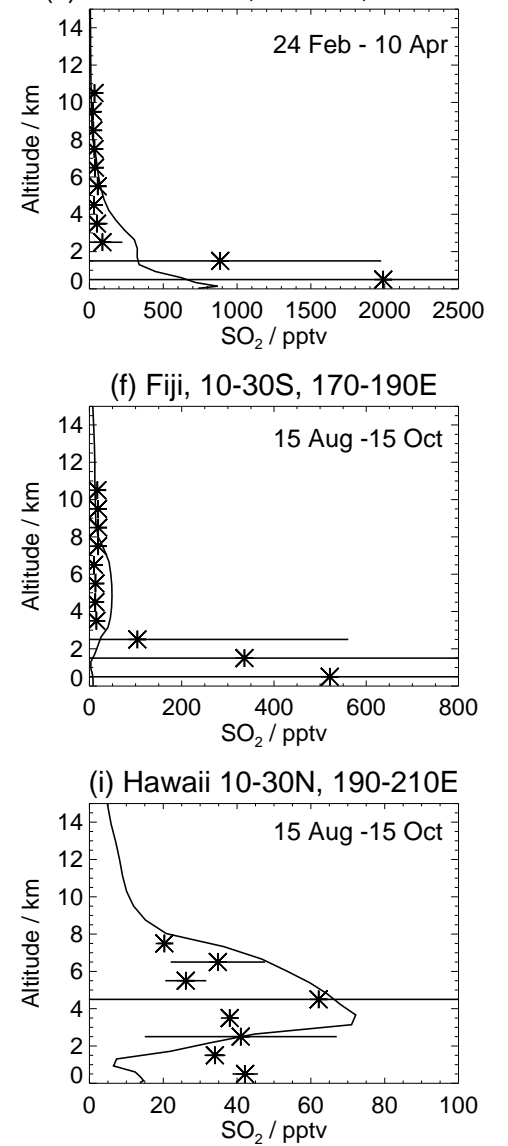

Fig. 8. Comparison of modelled (solid line) and observed (stars) vertical profiles of $\mathrm{SO}_{2}$. Error bars show \pm 1 standard deviation in the observations. Observations are from (a) Thornton et al. (1993), (b) Berresheim et al. (1990), (c-d) TRACE-P, (e-i) PEM-Tropics A (Emmons et al., 2000).

allow easy comparison with observations $\mathrm{CN}$ are reported as the concentration of particles $>3 \mathrm{~nm}$ diameter, which corresponds to the detection limit of current instruments (Stolzenburg and McMurry, 1991). CCN are reported at $0.2 \%$ supersaturation, which is typical of marine stratocumulus clouds, and corresponds to the activation of particles having a dry diameter of about $70 \mathrm{~nm}$. All concentrations have been converted to conditions of standard temperature and pressure (STP, $273 \mathrm{~K}$ and $1 \mathrm{~atm}$ ).

Smallest CN number concentrations are found in remote marine areas and largest concentrations are found near anthropogenically polluted regions. Simulated remote MBL $\mathrm{CN}$ concentrations are typically $250-500 \mathrm{~cm}^{-3}$, which compares well with observations (Clarke et al., 1987; Fitzgerald, 1991; Andreae et al., 1994, 1995; Pandis et al., 1995; Covert et al., 1996; Raes et al., 2000). GLOMAP simulates an air-mass weighted mean MBL CN concentration of $465 \mathrm{~cm}^{-3}$ for the year 1996 (but using 1985 anthropogenic sulfur emissions). A remote MBL concentration (averaged over gridboxes where the average age of air since last con- tinental contact is greater than $120 \mathrm{~h}$ ) of $430 \mathrm{~cm}^{-3}$ is simulated. Observations made on surface ship cruises during the MAGE92, RITS93 and RITS94 field campaigns (Quinn et al., 1995; Covert et al., 1996) in the central Pacific Ocean $\left(155^{\circ}-130^{\circ} \mathrm{W}, 32^{\circ} \mathrm{S}-20^{\circ} \mathrm{N}\right.$ ) measured average $\mathrm{CN}_{12}$ (particles larger than $12 \mathrm{~nm}$ diameter) concentrations of $325 \mathrm{~cm}^{-3}$. GLOMAP $\mathrm{CN}_{12}$ averaged over the same months and model grid squares as the measurements was $330 \mathrm{~cm}^{-3}$. This compares to $190 \mathrm{~cm}^{-3}$ simulated by the sulfate only model of Adams and Seinfeld (2002). Lack of sea salt aerosol will be responsible for some, but not all, of their underprediction of aerosol number.

Heintzenberg et al. (2000) have combined observed MBL $\mathrm{CN}$ concentrations from a variety of datasets taken over the past 30 years to produce a global annual average meridional distribution. Figure 10 compares annual mean GLOMAP CN against these latitudally binned observations. Total observed particle number varied between 200 and $800 \mathrm{~cm}^{-3}$ which is captured well by the model. However, the observations show a peak in $\mathrm{CN}$ concentrations in the $\mathrm{SH}$ midlatitudes 

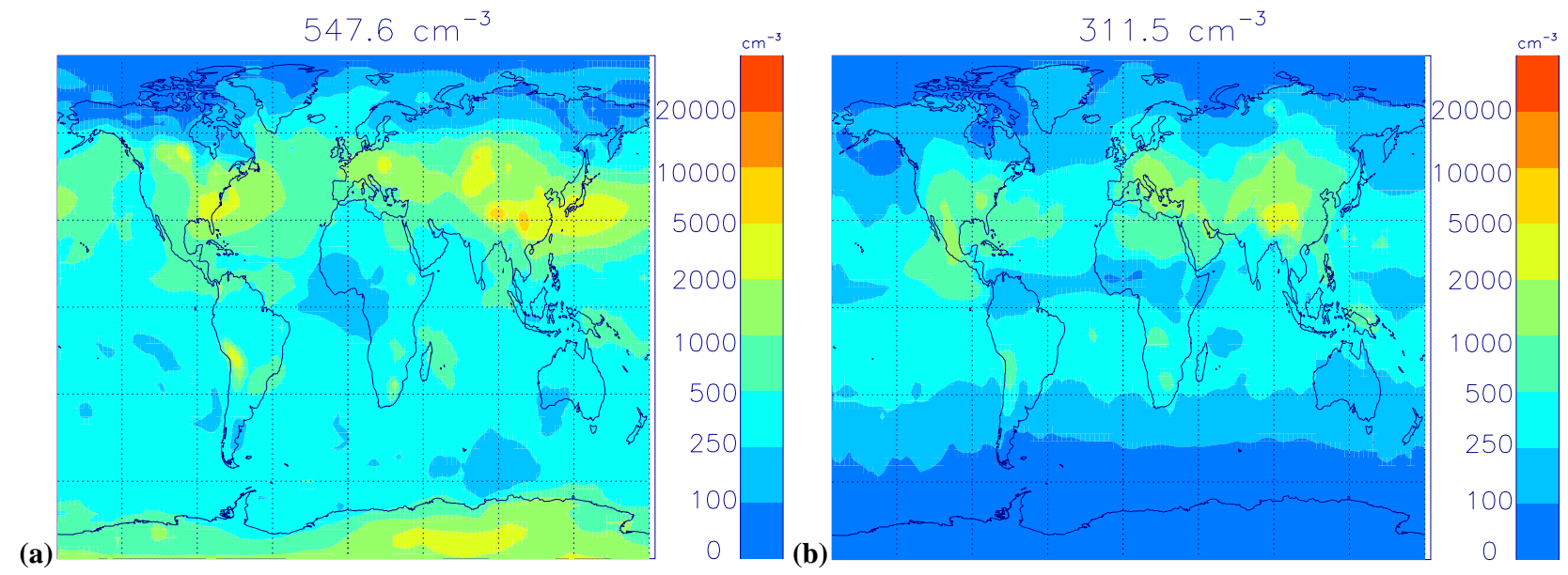

Fig. 9. Simulated monthly mean surface level CN concentrations $\left(\mathrm{cm}^{-3}\right)$ at standard temperature and pressure for (a) December 1995 and (b) July 1997. Values above each plot represent simulated surface layer, air-mass weighted average.

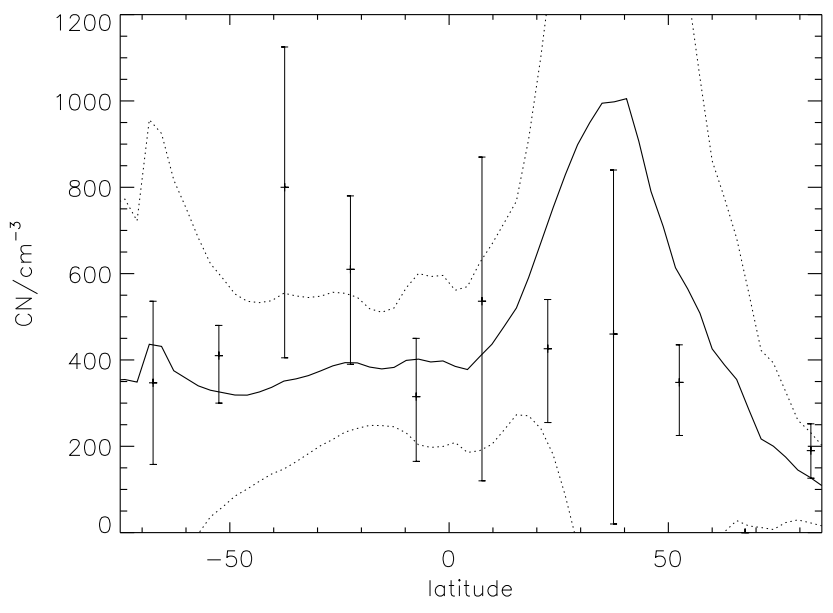

Fig. 10. Global annual average, meridional $\mathrm{CN}$ concentrations $\left(\mathrm{cm}^{-3}\right)$. Solid line shows GLOMAP zonal, annual mean for ocean grid squares. Dashed line are GLOMAP mean \pm 1 standard deviation in the daily model values. Crosses show mean of observations from Heintzenberg et al. (2000). Error bars show one standard deviation in the observations.

which is not simulated by GLOMAP. The MIRAGE model (Easter et al., 2004) also underpredicts CN concentrations in $\mathrm{SH}$ midlatiudes. Observations in the SH may not be representative of the annual cycle as they are heavily weighted by the ACE1 dataset which occurred in the SH summer.

Over the United States, Europe and East and Central Asia surface CN number concentrations of around 1000$5000 \mathrm{~cm}^{-3}$ are simulated. Table 4 compares observed and simulated particle number at some continental surface locations. GLOMAP underestimates $\mathrm{CN}$ number at all surface continental sites. GLOMAP does not include carbonaceous aerosol sources which may be an important component of aerosol number concentrations in polluted regions (Van Dingenen et al., 1995). An alternative explanation may the lack of a realistic aerosol nucleation scheme for boundary layer conditions. Adams and Seinfeld (2002) also underpredict polluted BL CN concentrations unless special care is taken to simulate particles that are formed close to point sources of pollution. Downwind of point sources of pollution, such as power plant plumes, secondary particle formation occurs on very small spatial scales (within 10s of kilometres of the pollution source). These sub-grid features cannot be captured by the model. Adams and Seinfeld (2002) simulate this source of particles by including $3 \%$ of anthropogenic sulfur emissions directly as particles. This mechanism is discussed further in Spracklen et al. (2005).

Simulated CN concentrations increase with altitude (Fig. 11), with maximum concentrations simulated in the upper troposphere (UT), as has been observed in recent field campaigns (e.g., Clarke et al., 1999) and simulated in models (Adams and Seinfeld, 2002). Simulated UT concentrations in the tropics peak at higher concentrations and at higher altitudes than at mid latitudes.

GLOMAP annual average global mean CN concentrations peak at $12800 \mathrm{~cm}^{-3}$ at a pressure of $275 \mathrm{hPa}$. This number concentration is about a factor of 6 higher than the annual global mean simulated by Adams and Seinfeld (2002) in their base case and a factor of 3-4 higher than simulated in their enhanced nucleation scenario (where the nucleation threshold was reduced by a factor of 10). Adams and Seinfeld (2002) do not attempt to model nucleation explicitly due to the large uncertainties in nucleation rates. Instead, condensation is assumed to occur for a full timestep and then nucleation takes place until the gas-phase $\mathrm{H}_{2} \mathrm{SO}_{4}$ concentration is reduced to a calculated nucleation threshold. However, this approach may increase the proportion of gas-phase 
Table 4. Observed and simulated particle number concentrations at surface continental sites. Model values are annual means for 1996 (with 1985 anthropogenic sulfur emissions). Number concentrations are for $\mathrm{CN}$ (particle diameters greater than $3 \mathrm{~nm}$ ) or $\mathrm{N}_{10}$ (particles greater than $10 \mathrm{~nm}$ diameter). The reason for the discrepancy between the model and observations is discussed in Sect. 4.1

\begin{tabular}{lllll}
\hline Location & Time & \multicolumn{2}{c}{ CN Number $/ \mathrm{cm}^{-3}$} & Reference \\
& & Observed & Simulated & \\
\hline Melpitz, Germany $\left(51^{\circ} 3^{\prime} \mathrm{N}, 12^{\circ} 6^{\prime} \mathrm{E}\right)$ & Mar 1996-Aug 1997 & 4830 & 3480 & Birmili et al. (2001) \\
Hyytiälä, Finland $\left(61^{\circ} 51^{\prime} \mathrm{N}, 4^{\circ} 17^{\prime} \mathrm{E}\right)$ & Feb 1996-Jan 1997 & 1813 & 586 & Mäkelä et al. (2000) \\
Oklahoma, USA $\left(36^{\circ} 36^{\prime} \mathrm{N}, 97^{\circ} 29^{\prime} \mathrm{W}\right)$ & Jul 1996-Jun 2000 & $4500\left(\mathrm{~N}_{10}\right)$ & $883\left(\mathrm{~N}_{10}\right)$ & Sheridan et al. (2001) \\
USA (various field campaigns) & $1970 \mathrm{~s}$ & 8600 & 1600 & Whitby (1978) \\
\hline
\end{tabular}
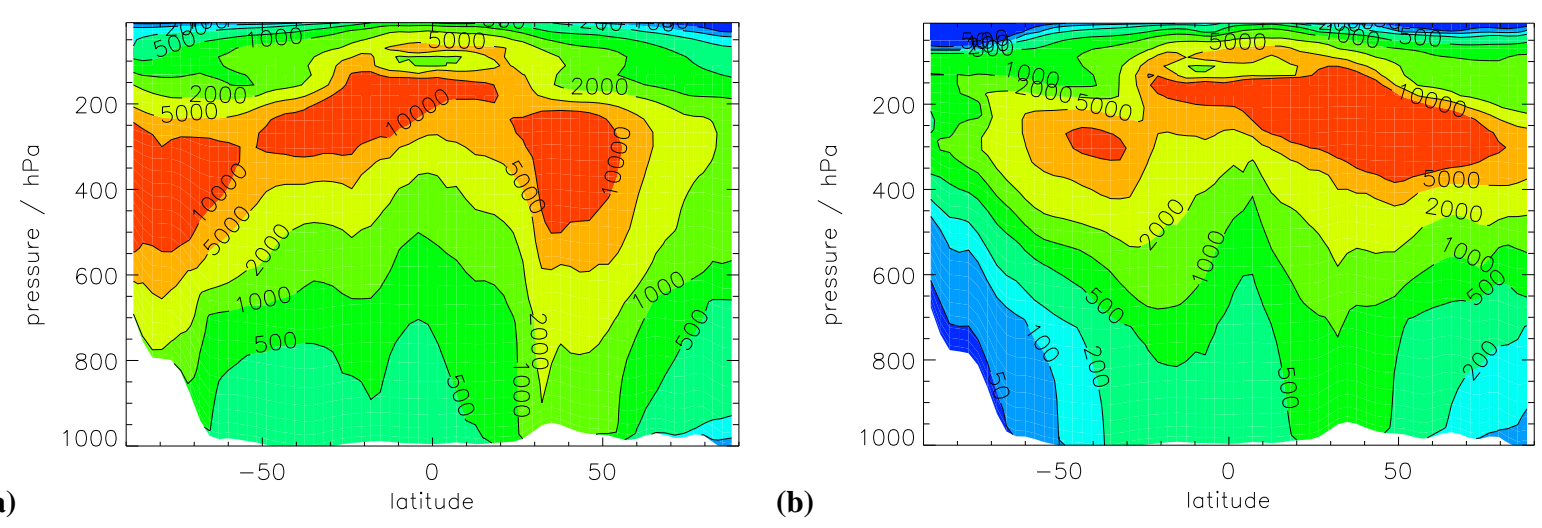

Fig. 11. Simulated zonal monthly mean $\mathrm{CN}$ concentrations $\left(\mathrm{cm}^{-3}\right)$ at standard temperature and pressure for (a) December 1995 and (b) July 1997.

$\mathrm{H}_{2} \mathrm{SO}_{4}$ condensing on existing aerosol rather than nucleating to form new particles, causing an underprediction of particle formation. GLOMAP annual average global mean $\mathrm{CCN}$ concentrations are about $145 \mathrm{~cm}^{-3}$ in the BL. This is about a factor of 2 higher than the base case from Adams and Seinfeld (2002) and about 20\% higher than in their enhanced nucleation scenario.

Clarke and Kapustin (2002) produced a mean vertical $\mathrm{CN}$ profile by averaging observed $\mathrm{CN}$ concentrations from GLOBE-2 (May 1990), ACE-1 (November 1995), PEMTropics A (September 1996) and B (March 1999) missions over $1 \mathrm{~km}$ altitude layers for the latitude bands $20^{\circ} \mathrm{S}-20^{\circ} \mathrm{N}$, $20^{\circ}-70^{\circ} \mathrm{N}, 20^{\circ}-70^{\circ} \mathrm{S}$. All observations are over the Pacific and Southern Oceans. Figure 12 shows GLOMAP annual mean $\mathrm{CN}$ concentrations averaged over the same model grid squares as the observations $\left(175^{\circ}-270^{\circ} \mathrm{E}\right.$ for the tropics, $200^{\circ}-240^{\circ}$ for the $\mathrm{NH}$ and $135^{\circ}-180^{\circ}$ for the $\left.\mathrm{SH}\right)$. GLOMAP captures the observed order of magnitude increase in $\mathrm{CN}$ concentrations between the surface and $10 \mathrm{~km}$ altitude. In the $\mathrm{NH}$ and SH the model accurately simulates the altitude of the observed UT CN maxima but overpredicts actual concentrations by up to a factor of 3 . In the tropics the model predicts the maximum observed concentration quite accurately but at an altitude of about $2 \mathrm{~km}$ higher than observed. Observations

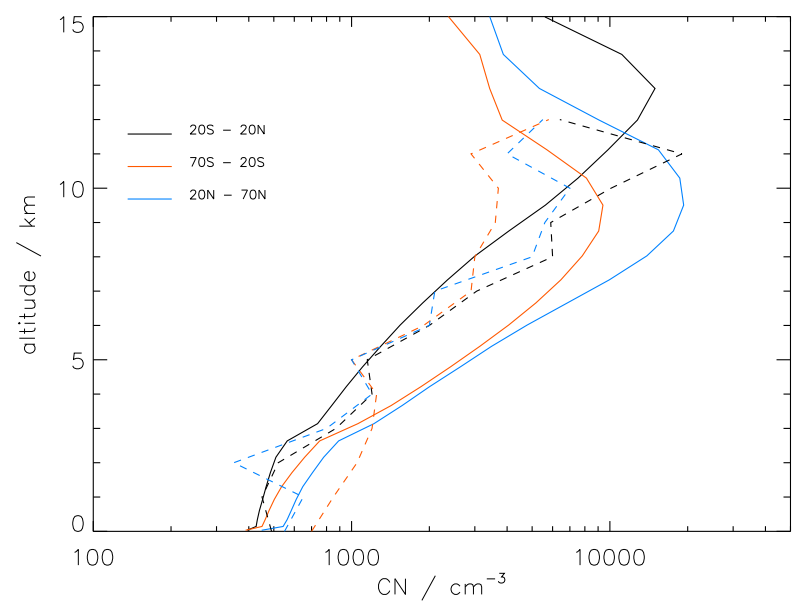

Fig. 12. Simulated (solid line) and observed (dashed line) (Clarke and Kapustin, 2002) vertical profiles of CN concentrations (at STP) over the Pacific and Southern Oceans.

in the $\mathrm{SH}$ are dominated by the ACE-1 data which may not be representative of the annual mean.

Figure 13 shows daily average altitude profiles of $\mathrm{CN}$ number and volume concentration over the remote South 
(a)

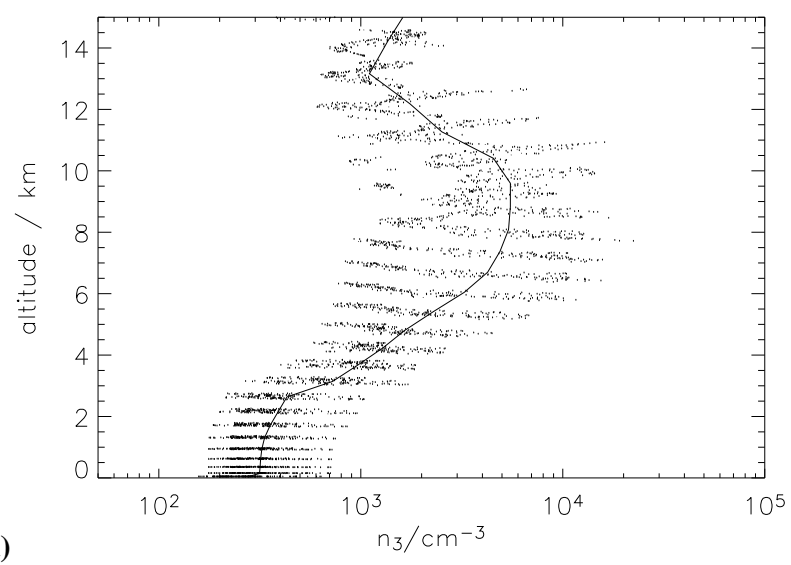

(b)

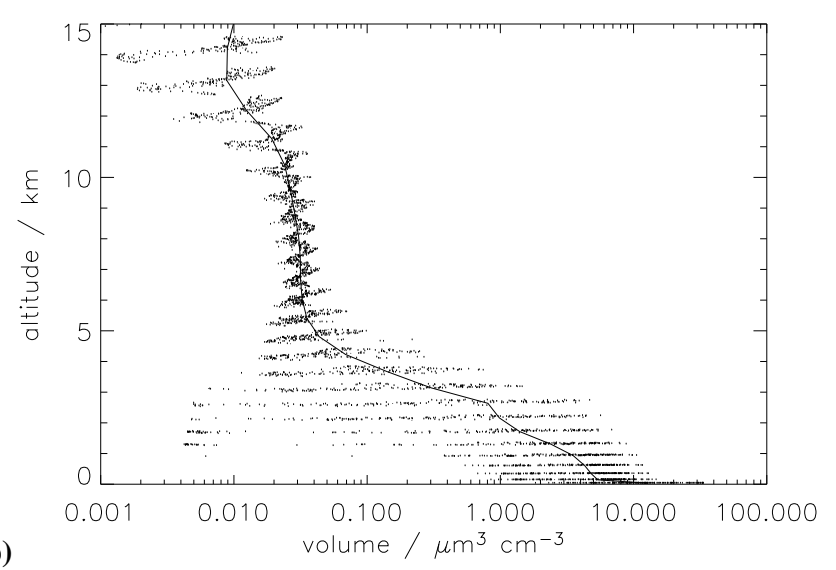

Fig. 13. Daily averaged vertical profiles over the South Pacific $\left(50^{\circ}-60^{\circ} \mathrm{S}, 210^{\circ}-270^{\circ} \mathrm{E}\right)$ of (a) $\mathrm{CN}$ number concentrations $\left(\mathrm{cm}^{-3}\right)$ and (b) Volume $\left(\mu \mathrm{m}^{3} \mathrm{~cm}^{-3}\right)$ at standard temperature and pressure on 1 December 1995. The solid line shows the spatial mean and the dots show individual 24-h average grid point values.

(a)

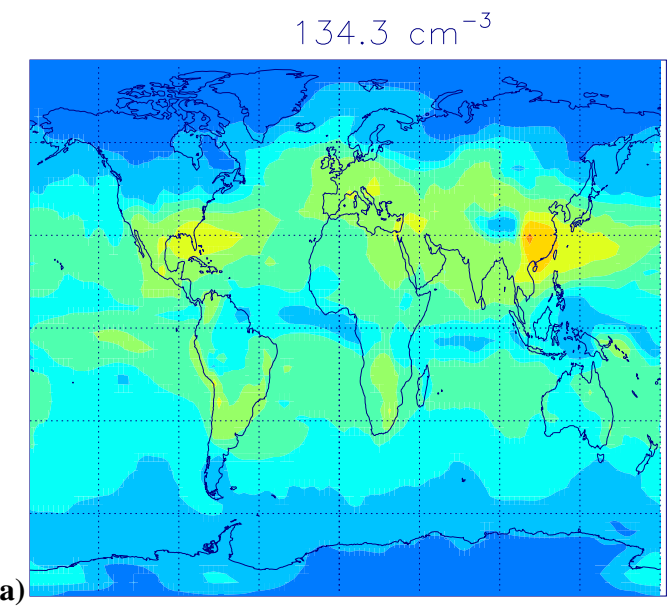

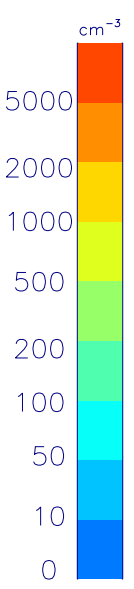

(b)

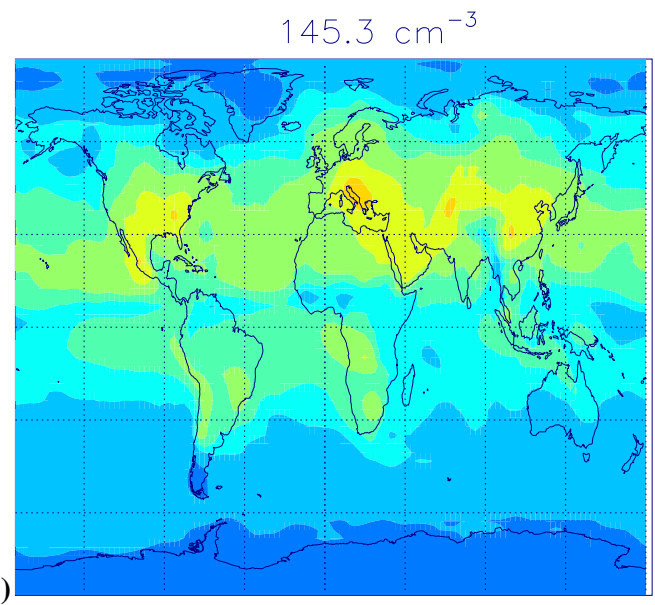

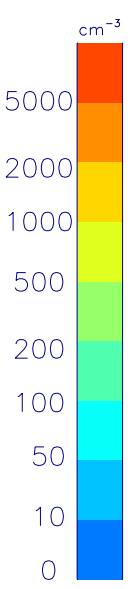

Fig. 14. As for Fig. 9 but for $\mathrm{CCN}$ (at $0.2 \%$ supersaturation)

Pacific Ocean. Simulated CN concentrations increase by about an order of magnitude between the surface and $10 \mathrm{~km}$ altitude, as has been observed in a variety of field campaigns (e.g., Clarke and Kapustin, 2002). Maximum CN concentrations at this location are simulated at around $9 \mathrm{~km}$ altitude. Simulated dry volume concentrations are greatest at the surface $\left(1-15 \mu \mathrm{m}^{3} \mathrm{~cm}^{-3}\right)$ and decrease with increasing altitude (to about $0.02-0.05 \mu \mathrm{m}^{3} \mathrm{~cm}^{-3}$ at $10 \mathrm{~km}$ ), as has been observed (Clarke and Kapustin, 2002). Figure 13 also gives an indication of the instantaneous spatial variability in aerosol number and volume in a limited region. Notice, for example, the greater than 2 orders of magnitude variability in aerosol volume between 1 and $3 \mathrm{~km}$ altitude that arises due to cloud scavenging processes.

Figure 14 shows GLOMAP surface monthly mean number cloud condensation nuclei (CCN) concentrations (at $0.2 \%$ supersaturation) for July and December. Simulated CCN concentrations decrease with increasing altitude and concentrations are generally highest in polluted $\mathrm{NH}$ regions, with an obvious correlation between $\mathrm{CN}, \mathrm{CCN}$ and sources of anthropogenic $\mathrm{SO}_{2}$. Interestingly, $\mathrm{CN}$ concentrations are higher in winter than summer while CCN concentrations show the opposite (though less pronounced) seasonal variation. In winter, lower temperatures mean that nucleation can occur over a greater depth of the free troposphere (FT), which leads to higher surface $\mathrm{CN}$ concentrations. In summer, higher $\mathrm{OH}$ radical concentrations lead to greater production of gas phase sulfuric acid, which causes faster rates of condensational growth (while having little effect on the insignificant binary homogeneous nucleation rate). The lower number of available particles are able to grow faster, leading to higher $\mathrm{CCN}$ concentrations. Also apparent in Fig. 11 


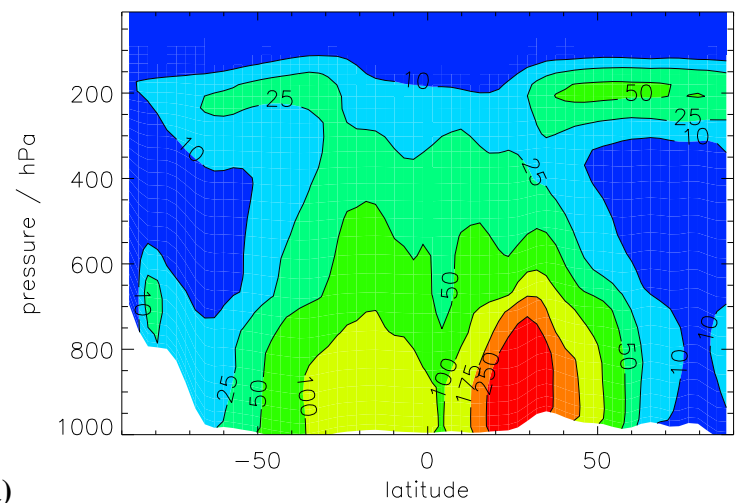

(a)

Fig. 15. As for Fig. 11 but for $\mathrm{CCN}$ (at $0.2 \%$ supersaturation)

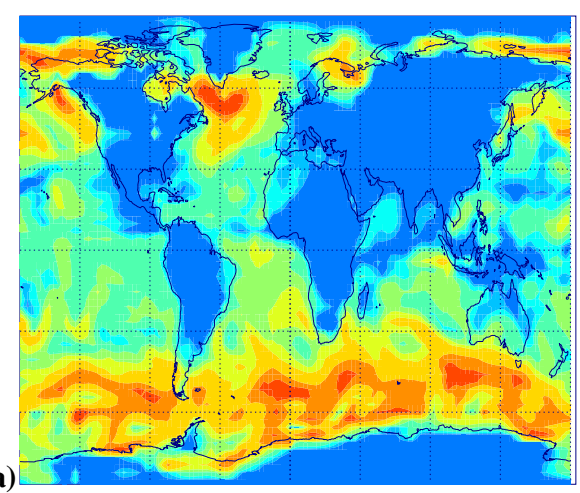

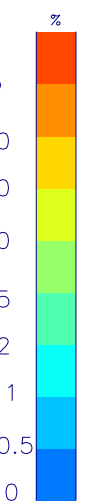

(a)

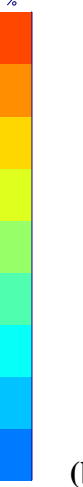

(b)

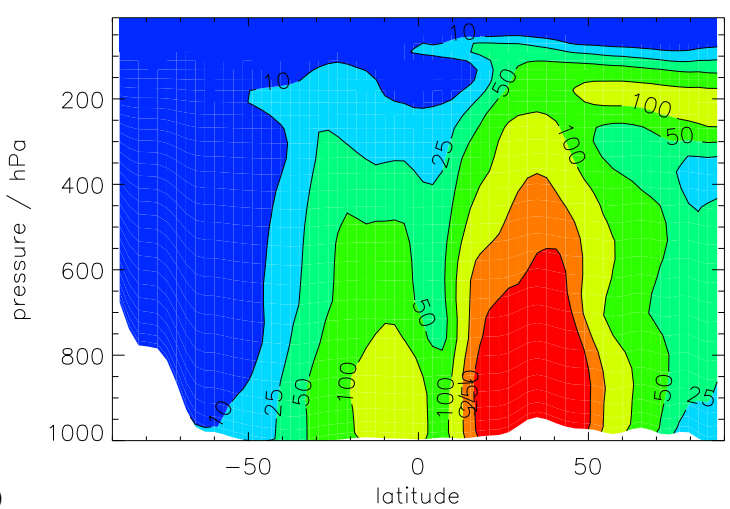

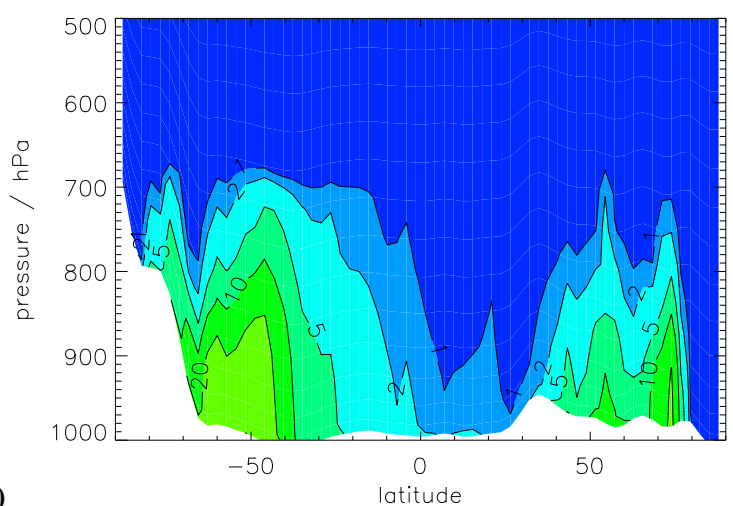

Fig. 16. Percentage contribution of sea spray to total CCN (at $0.2 \%$ supersaturation) for 1 December 1995 (24-h average) (a) Surface Level (b) Zonal mean.

is the vertical extension of the CCN-rich air into the summer FT, which is caused by more efficient vertical mixing of boundary layer air. CCN concentrations are also clearly depleted along the Inter-Tropical Convergence Zone (ITCZ) due to effective cloud scavenging processes.

\subsection{Contribution of sea spray to $\mathrm{CCN}$}

It is important to quantify the relative contribution of sea spray particles and other aerosols to MBL CCN for several reasons. Firstly, oceanic regions have low natural aerosol concentrations and are therefore susceptible to modification due to inputs from anthropogenic emissions. Secondly, the sea spray source function is particularly uncertain for particles with sizes less than $1 \mu \mathrm{m}$, and it is particles of this size that contribute most to the CCN number. Thirdly, the climate response to changes in emissions of DMS depends on the changes in $\mathrm{CCN}$ resulting from new sulfate particles in the MBL.

The relative contribution of sea spray and sulfate particles to MBL CCN is uncertain and dependent on location and at- mospheric conditions. Blanchard and Cipriano (1987) measured background MBL sea spray particle concentrations of between 15 and $20 \mathrm{~cm}^{-3}$. O'Dowd et al. (1999) observed that $10 \%$ of the accumulation mode aerosol was derived from sea spray particles in the Pacific Ocean MBL ( $600 \mathrm{~km}$ off the coast of California with wind speeds of less than $10 \mathrm{~ms}^{-1}$ ) and that about $30 \%$ of total aerosol concentration was sea salt in the North Atlantic MBL (with wind speed up to $17 \mathrm{~ms}^{-1}$ ). Yoon and Brimblecombe (2002) used a box model to predict that more than $70 \%$ of MBL CCN were derived from sea salt where wind speeds were moderate to high, especially in winter seasons in middle to high latitude regions.

Figure 16 shows the model calculation of the contribution of sea spray to total CCN. This was calculated by comparing a baseline model run with sulfate and sea spray sources to a run where only sea spray emissions were included. In our model simulations most of the sulfate aerosol formation and growth to $\mathrm{CCN}$ sizes occurs in low temperature regions lying well above the MBL, so our estimate of relative contributions to $\mathrm{CCN}$ based on two separate simulations is likely 

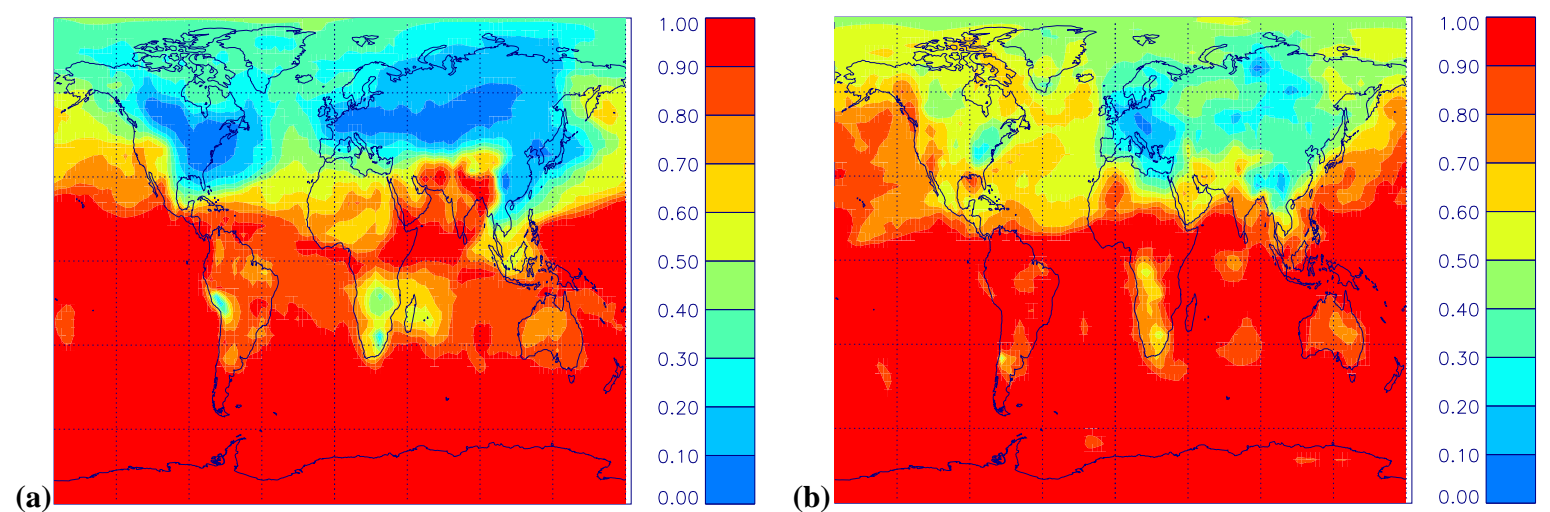

Fig. 17. Simulated fractional contribution of natural sulfur and sea salt aerosol to monthly mean surface $\mathrm{CN}$ concentrations $\left(\mathrm{cm}^{-3}\right.$ at $\mathrm{STP}$ conditions of $273 \mathrm{~K}$ and $1 \mathrm{~atm}$ ). (a) December 1995 and (b) July 1997.

to be reasonable. More accurate estimates will be possible in a multicomponent version of GLOMAP currently under development.

In the tropical oceanic MBL the model predicts that sea spray contributes less than $10 \%$ to total CCN. The remaining $90 \%$ are derived mostly from sulfate particles that formed in the free and upper troposphere. The importance of the UT as a source of tropical MBL aerosol is apparent in a run in which aerosol nucleation was switched off below $3 \mathrm{~km}$, which showed little change in MBL sulfate aerosol (not shown here). In the $30-60^{\circ}$ oceanic belt sea spray generally contributes between 20 and $75 \%$ of total MBL CCN. In the continental boundary layer sea spray contributes less than $1 \%$ to total CCN.

\subsection{Contribution of anthropogenic emissions to $\mathrm{CN}$ and $\mathrm{CCN}$}

The first step in determining direct and indirect aerosol forcing is to calculate how global aerosol distributions have changed from pre-industrial times to the present day. Here, GLOMAP is run with natural sulfur emissions (volcanic $\mathrm{SO}_{2}$ and DMS) and sea salt only and compared to the baseline model run which includes anthropogenic $\mathrm{SO}_{2}$ emissions as well as natural emissions. Total sulfur emissions for the preindustrial model run is $25.3 \mathrm{Tg} \mathrm{S} \mathrm{yr}^{-1}$ compared to 92.3 $\mathrm{Tg} \mathrm{S} \mathrm{yr}^{-1}$ with anthropogenic and natural emissions.

Sea salt and natural sulfur emissions contribute $61 \%$ to (air-mass weighted) surface $\mathrm{CN}$ number in December $(74 \%$ in July), and $41 \%$ to (air-mass weighted) surface CCN number in December (39\% in July). These contributions of natural sulfur to global CN are much greater than the $27 \%$ contribution of natural sulfur to total sulfur emissions. Adams and Seinfeld (2002), for a sulfate only aerosol model, present annual mean figures of natural emissions contributing $95 \%$ to $\mathrm{CN}$ and $40 \%$ to $\mathrm{CCN}$. The difference in estimates of the contribution of natural emissions to $\mathrm{CN}$ number may be due to Adams and Seinfeld (2002) not explicitly calculating nucleation. This may make their the model less sensitive to changes in sulfur concentrations, as any increase in gasphase $\mathrm{H}_{2} \mathrm{SO}_{4}$ may cause additional condensation to occur rather than additional particle formation.

Earlier sulfur models have also been used to calculate the contribution of natural and anthropogenic sulfur to the total sulfate aerosol mass. Chin et al. (2000) found that 33\% of total sulfate came from natural emissions (where natural sulfur emissions accounted for $20 \%$ of total sulfur), whereas Chin and Jacob (1996) found 63\% came from natural emissions (which accounted for 30\% of total sulfur). Chin et al. (2000) attributed the difference between the two models to slower rates of sulfate production from DMS and less effective wet scavenging in the mid latitudes in their work than in that of Chin and Jacob (1996).

Figures 17 and 18 show the simulated fractional contribution of natural sulfate and sea-salt aerosol to simulated monthly mean surface $\mathrm{CN}$ and $\mathrm{CCN}$ concentrations. In the SH, MBL CN concentrations are dominated by natural sources, with generally greater than $90 \%$ of $\mathrm{CN}$ number coming from DMS and sea salt. In contrast, over continental regions in the $\mathrm{NH}$, the preindustrial run has as low as $10 \%$ of the baseline surface CN number. Over Europe, Asia and eastern US surface $\mathrm{CCN}$ concentrations are generally less than $20 \%$ of the baseline case. In the SH MBL, greater than $70 \%$ of $\mathrm{CCN}$ are natural in origin, and in the $\mathrm{SH} 30^{\circ}-60^{\circ}$ oceanic belt more than $90 \%$ of $\mathrm{CCN}$ is natural in origin with the majority arising from sea salt (Fig. 16).

Figure 19 shows the fractional contribution to zonal mean $\mathrm{CN}$ and $\mathrm{CCN}$ concentrations. In the $\mathrm{NH}$, the contribution to $\mathrm{CN}$ number from anthropogenic sources is more horizontally dispersed in December but reaches higher altitudes in July. This was also found for the anthropogenic contribution to total sulfate (Chin et al., 2000). In the SH, mid to high latitudes $\mathrm{CN}$ number is dominated by natural emissions at all altitudes whereas CCN number is only dominated by 
(a)

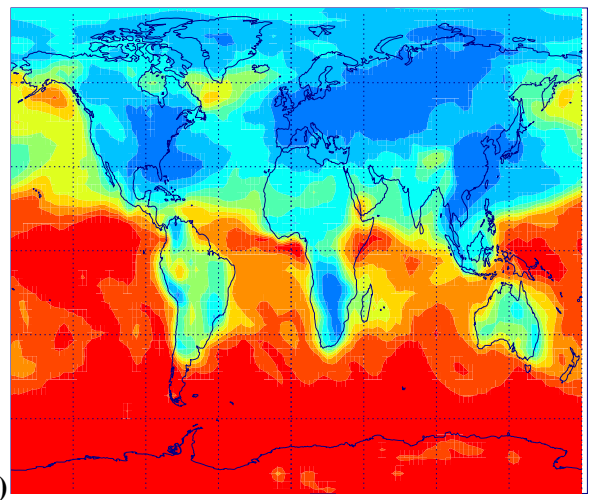

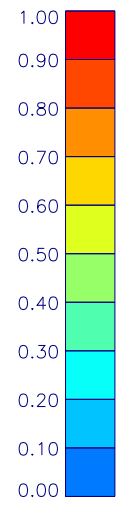

(b)

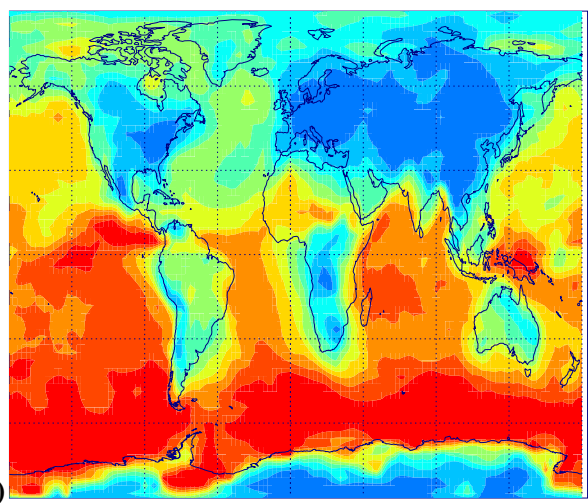

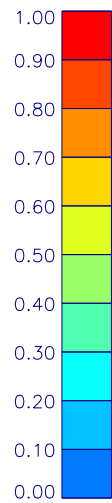

Fig. 18. Simulated fractional contribution of natural sulfur and sea salt aerosol to monthly mean surface $\mathrm{CCN}$ concentrations ( $\mathrm{cm}^{-3}$ at STP conditions of $273 \mathrm{~K}$ and $1 \mathrm{~atm}$ ). (a) December 1995 and (b) July 1997.

\section{$\mathrm{CN}$}

(a)

(b)
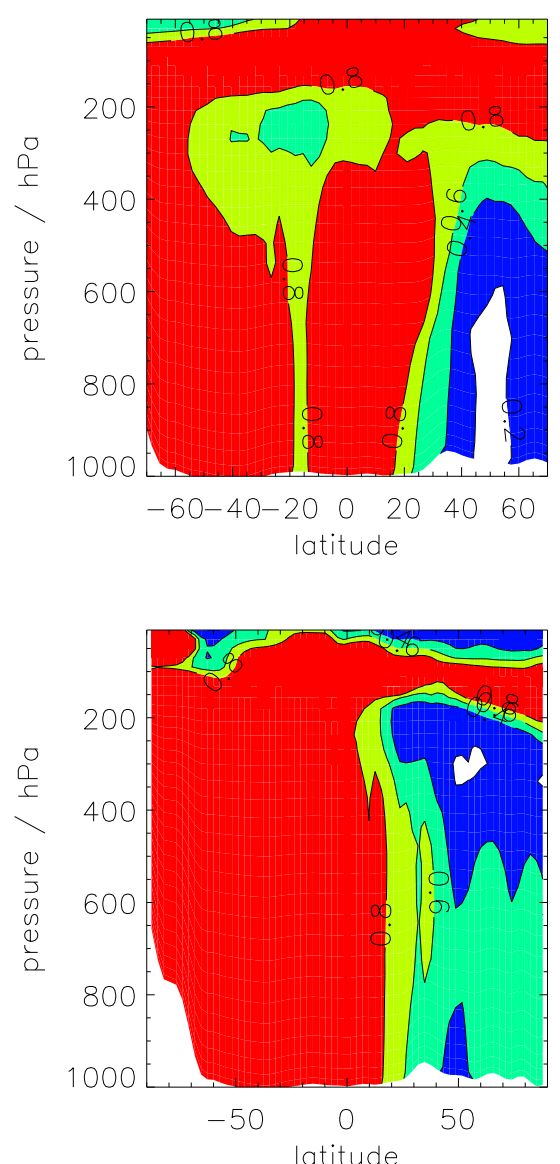

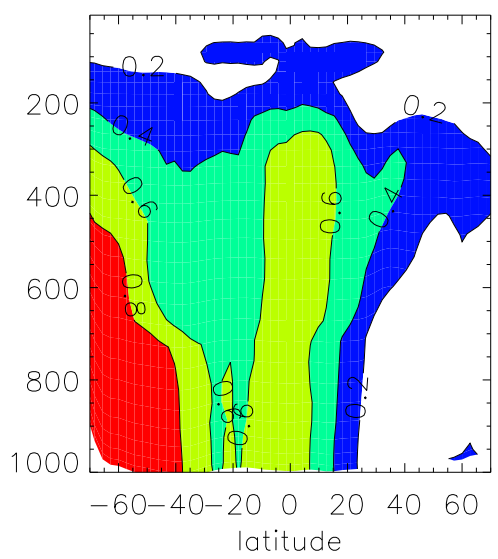

\section{$\mathrm{CCN}$}

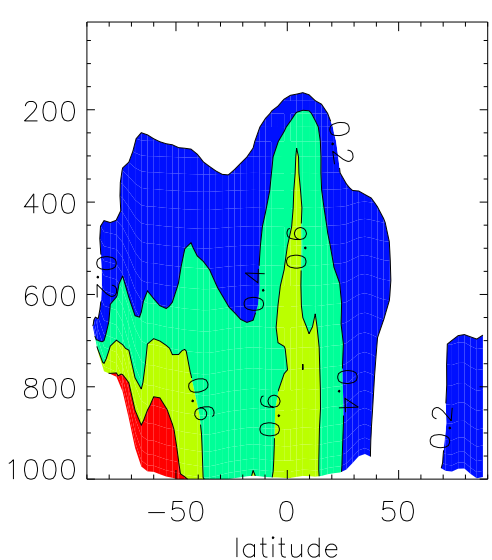

Fig. 19. Simulated fractional contribution of natural sulfur and sea salt aerosol to monthly mean zonal average CN and CCN concentrations $\left(\mathrm{cm}^{-3}\right)$ at STP conditions of $273 \mathrm{~K}$ and $1 \mathrm{~atm}$. (a) December 1995 and (b) July 1997. 
natural emissions near the surface. The natural contribution to $\mathrm{CCN}$ number decreases with altitude in the SH. Chin et al. (2000) found a similar result with sulfate concentrations and attributed this to interhemispheric transport from the $\mathrm{NH}$ and convective transport from midlatitudes.

\subsection{Particle size distributions}

The global aerosol distribution was simulated using 20 aerosol size bins. For simplicity, the results can be displayed as four typical size classes based on dry diameter $\left(\mathrm{D}_{p}\right)$ : nucleation $\left(\mathrm{D}_{p}<7 \mathrm{~nm}\right)$, Aitken $\left(7 \mathrm{~nm}<\mathrm{D}_{p}<65 \mathrm{~nm}\right)$, accumulation $\left(65 \mathrm{~nm}<\mathrm{D}_{p}<700 \mathrm{~nm}\right)$ and coarse particles $\left(\mathrm{D}_{p}>700 \mathrm{~nm}\right)$. Figures 20 and 21 show surface level and zonal mean aerosol concentrations divided into these four size ranges for December and July. These are typically accepted ranges that are convenient for dividing the aerosol distribution. However, it does not imply the presence of genuinely distinct modes in the modelled size distribution.

Coarse mode aerosol concentrations are much greater over oceanic areas because these particles are derived from emission of sea spray. Large particles are subject to fast deposition rates and and are not advected far from their source regions, resulting in strong concentration gradients at landocean boundaries. Model emission rates of sea spray particles depend only on the surface wind speeds, resulting in largest MBL concentrations where wind speeds are fastest: generally in the $30-50^{\circ} \mathrm{S}$ oceanic belt. Low concentrations are simulated near the equator due to the relatively low wind speeds there and the efficient removal of particles in tropical rain clouds.

Both coarse mode and accumulation mode concentrations are strongly depleted along the ITCZ. This is caused by cloud scavenging and convective precipitation effectively removing these larger particles. In contrast Aitken mode particles are not effectively removed by these processes as they do not serve as cloud condensation nuclei nor are they efficiently impaction scavenged by rain (Andronache, 2003), so no depletion is obvious along the ITCZ.

As with the seasonal variation of $\mathrm{CN}$ and $\mathrm{CCN}$, in the $\mathrm{NH}$ winter Aitken mode concentrations are higher than in the NH summer whereas accumulation mode concentrations are higher in $\mathrm{NH}$ summer than $\mathrm{NH}$ winter. In the $\mathrm{SH}$ winter, concentrations of both Aitken and accumulation mode aerosol are reduced due to the lack of DMS emissions.

The model simulates low concentrations of nucleation mode particles at the surface and their distribution is much more patchy than other size classes. The MBL tends to have temperatures that are too high for $\mathrm{H}_{2} \mathrm{SO}_{4}-\mathrm{H}_{2} \mathrm{O}$ binary nucleation to occur. Additionally, the large pre-existing aerosol surface area near the surface means that most of the available $\mathrm{H}_{2} \mathrm{SO}_{4}$ rapidly condenses onto the existing aerosol rather than forming new particles. In some marine areas concentrations of nucleation mode particles up to $250 \mathrm{~cm}^{-3}$ are simulated. These tend to occur in regions of low FT tem- peratures. Rapid vertical mixing can transport nucleation mode particles produced in the FT to the surface before they grow through coagulation and condensation to larger particles. However, there is a clear absence of nucleation mode aerosol where sulfur sources are very limited (see Figs. 3 and 4) even if FT temperatures are very low. This can be seen over the Antarctic continent during the SH winter where no nucleation mode aerosol is simulated. Examination of daily fields of accumulation mode aerosol in remote marine areas reveals an anti-correlation between accumulation mode number and nucleation mode number (not shown here). This will be due to low accumulation mode number resulting in low pre-existing particle surface area which allows gas phase $\mathrm{H}_{2} \mathrm{SO}_{4}$ concentrations to build up.

Nucleation and Aitken mode particle concentrations reach a maximum in the UT, with decreasing concentrations towards the surface. Downward transport of nucleation particles from the UT occurs simultaneously with their growth to Aitken mode particles, through coagulation and condensation. Accumulation mode and coarse mode particles have maximum concentrations at the surface. Coarse mode particles have a strong concentration gradient with altitude, with concentrations $10^{3}-10^{4}$ times lower at $400 \mathrm{hPa}$ than at the surface. This is due to very efficient removal processes by dry and wet deposition. As the model does not simulate gravitational settling of large particles from the upper to lower levels it is possible that the model overestimates the transport of large particles to higher altitudes. Accumulation mode particles are less efficiently removed and are transported to higher altitudes.

Figure 22 shows number and volume distributions as a function of dry particle diameter for December and July. For the North Atlantic MBL and FT, observed size distributions from Raes et al. (2000) are included for comparison. These observations are chosen as they are a climatology rather than measurements over a specific time period.

In the MBL the model captures the characteristic submicron bimodal number-size distribution (the smaller mode at about $20-80 \mathrm{~nm}$ diameter and the the larger mode between $100-500 \mathrm{~nm}$ diameter) and an additional mode in the supermicron range (Fitzgerald, 1991).

In the FT (at $2.3 \mathrm{~km}$ altitude) the model shows a typical FT unimodal distribution of particle concentration. However, comparison of model simulations with observations from Raes et al. (2000) over the North Atlantic shows that the model tends to emphasise a large (sea spray) mode at $>1 \mu \mathrm{m}$ which is not distinct in the observations.

The modelled North Atlantic size distribution is strongly perturbed by anthropogenic sulfur emissions, which, in both summer and winter, dominate the natural emissions. Aitken and accumulation mode particle concentrations greatly exceed those in the Southern Ocean where natural emissions dominate. The Southern Ocean nucleation and Aitken mode particles also show a lack of growth compared with those in the North Atlantic. Particle growth is even more limited in 

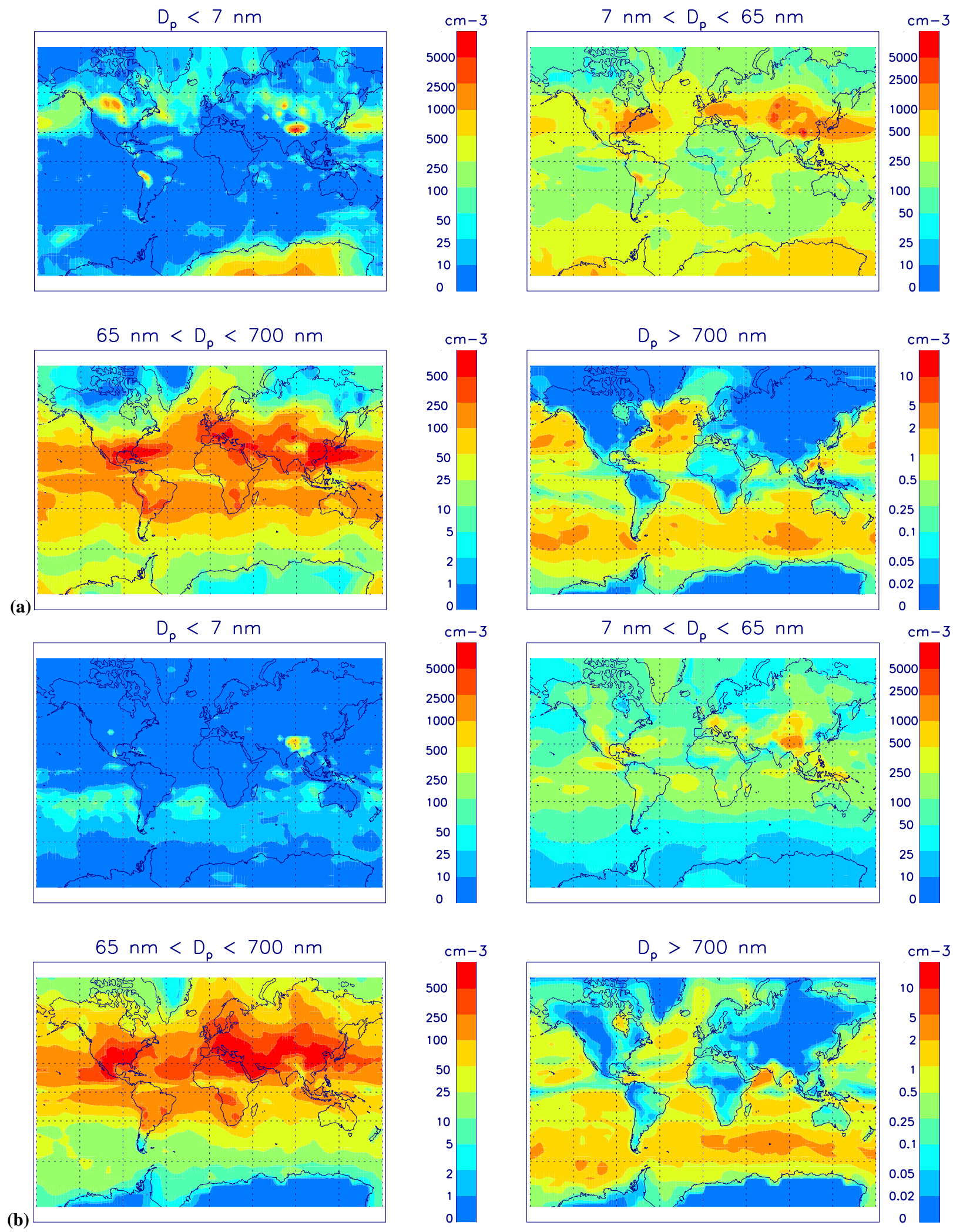

Fig. 20. Simulated monthly mean surface aerosol concentrations $\left(\mathrm{cm}^{-3}\right)$ for four dry aerosol diameter $\left(\mathrm{D}_{p}\right)$ size classes (at standard temperature and pressure) (a) December 1995 and (b) July 1997. 

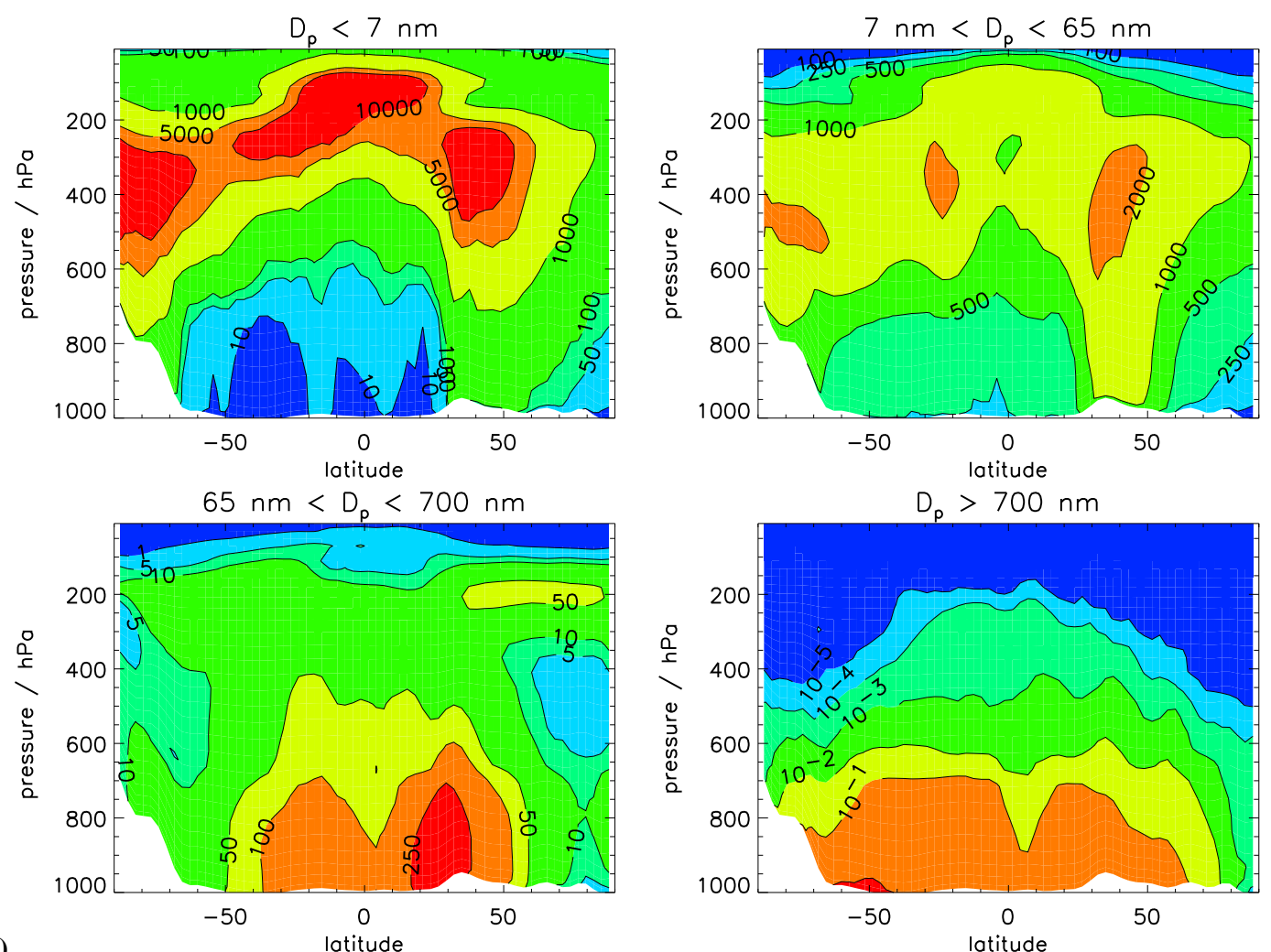

(a)
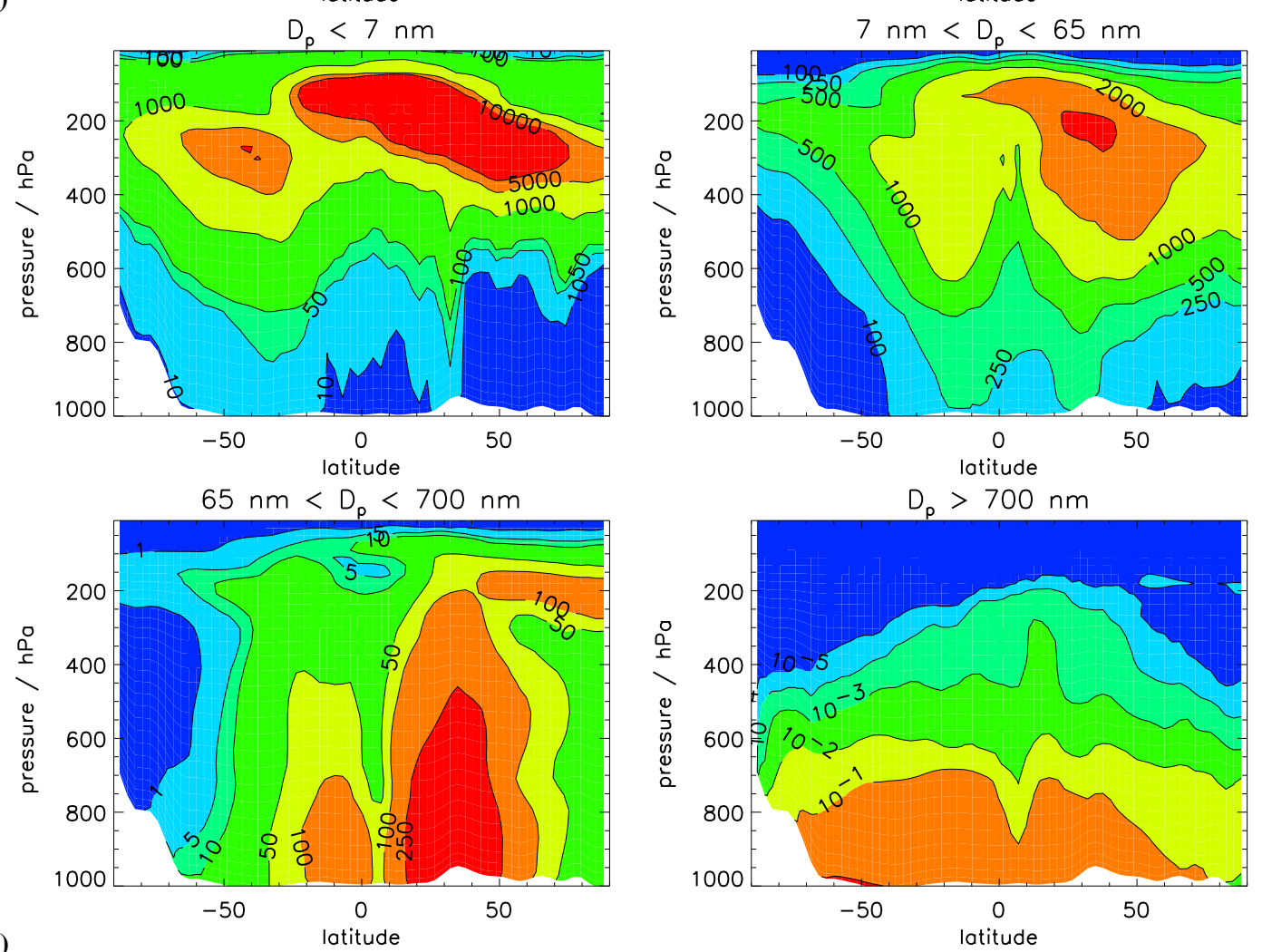

Fig. 21. Simulated monthly mean zonal aerosol concentrations $\left(\mathrm{cm}^{-3}\right)$ for four dry aerosol diameter $\left(\mathrm{D}_{p}\right)$ size classes $($ at standard temperature and pressure) (a) December 1995 and (b) July 1997. 

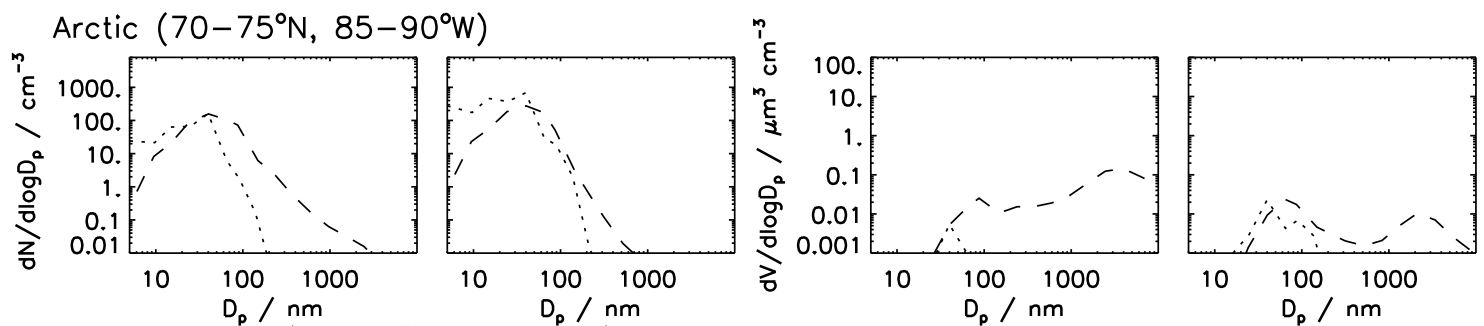

North Atlantic $\left(40-45^{\circ} \mathrm{N}, 30-35^{\circ} \mathrm{W}\right)$
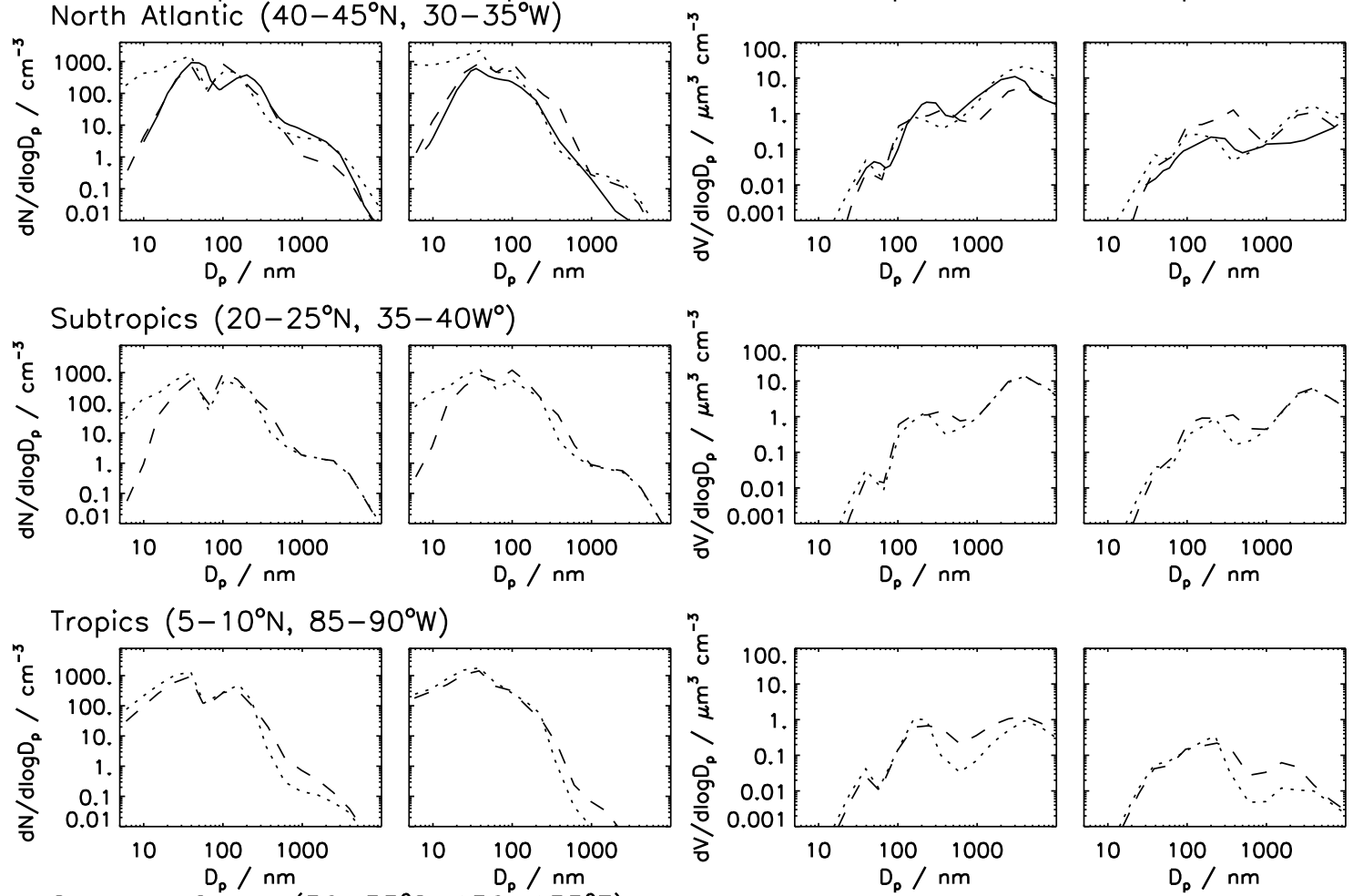

Southern Ocean $\left(50-55^{\circ} \mathrm{S}, 150-155^{\circ} \mathrm{E}\right)$
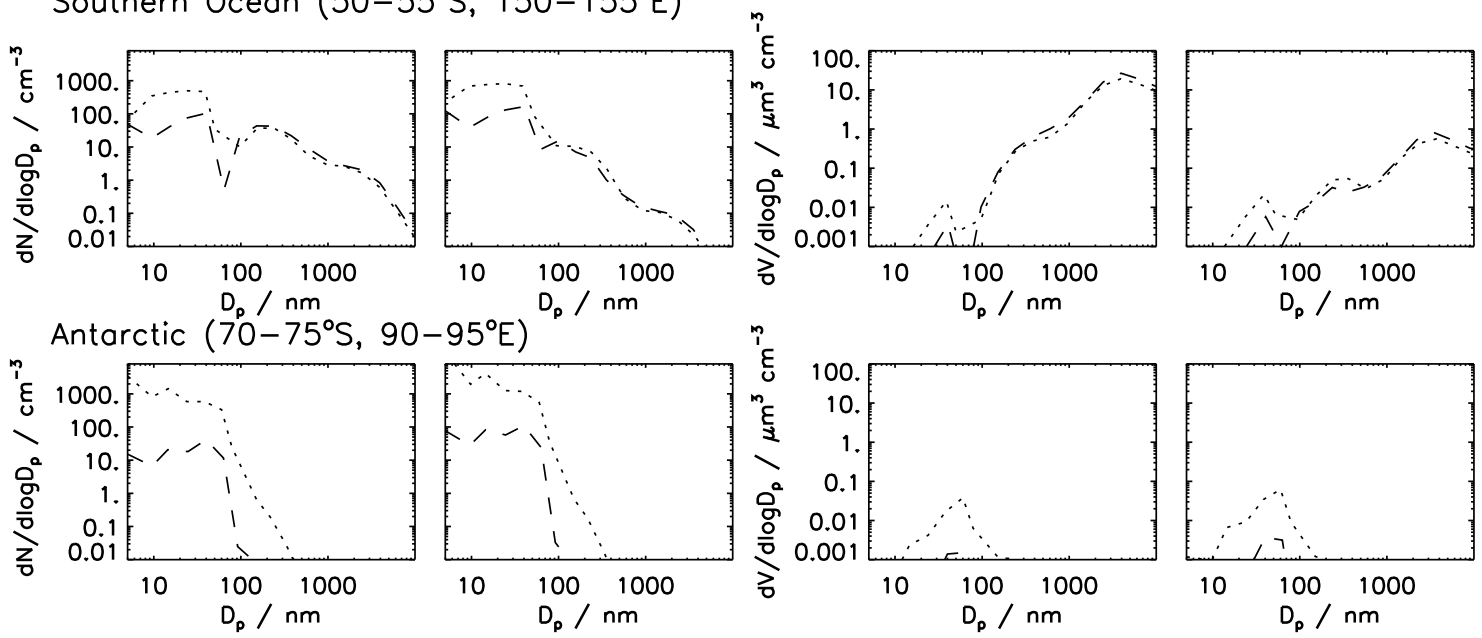

Fig. 22. Monthly averaged number and volume size distributions in the MBL and FT at various locations in December 1995 (dotted line) and July 1997 (dashed line). Observations (solid line) are for the North Atlantic in July (Raes et al., 2000). 


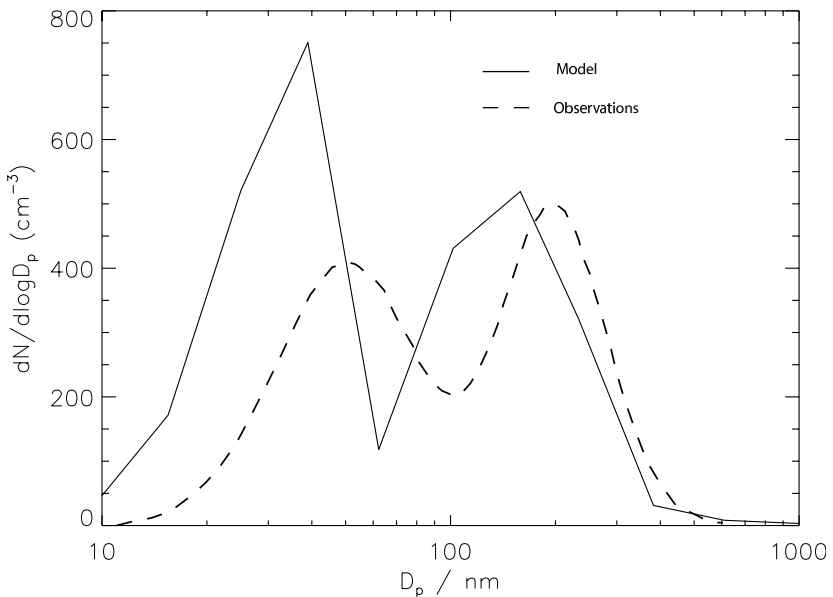

Fig. 23. Simulated and observed (Van Dingenen et al., 1995) aerosol size distributions for the North Atlantic MBL $\left(50^{\circ}-25^{\circ} \mathrm{W}\right.$ and $\left.30^{\circ}-45^{\circ} \mathrm{N}\right)$.

the Antarctic regions due to the very low sulfuric acid gas concentrations there.

Measurements of aerosol size distributions from the North Atlantic were taken during cruises between Nova Scotia and the Canary Islands during September-October 1992 as part of the Joint Global Ocean Flux Study (JGOFS) (Van Dingenen et al., 1995). High concentrations of carbonaceous aerosols (which are not simulated by GLOMAP) were observed within a few hundred kilometres of the continents. Here, in a similar approach to Adams and Seinfeld (2002), we compare with observed size distributions taken between $50^{\circ}-25^{\circ} \mathrm{W}$ and $30^{\circ}-45^{\circ} \mathrm{N}$, where relatively clean conditions were observed. An average number concentration of particles (between 16 and $1000 \mathrm{~nm}$ diameter) of $400 \mathrm{~cm}^{-3}$ was observed. GLOMAP slightly overpredicts this number, simulating $488 \mathrm{~cm}^{-3}$, while TOMAS underpredicts the number, simulating $150 \mathrm{~cm}^{-3}$ (Adams and Seinfeld, 2002). Figure 23 shows a comparison of the GLOMAP simulated size distribution against the lognormal fit to the observed data. Both simulated and observed distributions show a bimodal submicron distribution typical of the MBL. GLOMAP slightly underpredicts the size of both the Aitken and accumulation modes and the minimum between the two modes. The base case scenario of Adams and Seinfeld (2002) also underpredicts the size of the accumulation mode but captures the size of the Aitken mode quite accurately, while underpredicting Aitken mode number. We assume a different activation diameter in clouds to that used by the TOMAS model. They assume an activation of $82 \mathrm{~nm}$ in stratiform clouds and $33 \mathrm{~nm}$ in convective clouds. This diameter may result in different Aitken and accumulation modes sizes, as discussed in Spracklen et al. (2005). As discussed earlier, GLOMAP treats nucleation/condensation differently to TOMAS, which may partly explain the smaller and more numerous Aitken mode in GLOMAP. GLOMAP captures the number in the accumulation mode quite accurately whereas TOMAS underpredicts accumulation mode number. The Adams and Seinfeld (2002) model does not include sea salt, which will contribute to the observed accumulation mode. The higher activation diameter for in-cloud oxidation in TOMAS may also result in smaller accumulation mode number.

\section{Conclusions}

A new global off-line aerosol microphysics chemical transport model incorporating a sectional treatment of the aerosol size distribution has been developed and used to simulate the atmospheric distributions of sulfur gases and sulfate and sea spray aerosol. The global tropospheric aerosol was created in the model by spinning up from an initially aerosol-free atmosphere over a period of 60 days. This period is long enough for the aerosol size distribution in all parts of the atmosphere to become insensitive to the length of spin-up.

The model sulfur cycle compares well with a large number of previous global studies, and $\mathrm{SO}_{2}$ and DMS concentrations are in reasonable agreement with observations.

In the current configuration of the model we have simulated only sea spray and sulfate aerosol, with the latter formed through binary homogeneous nucleation. The model simulates realistic MBL CN concentrations of 250 $500 \mathrm{~cm}^{-3}$ over remote regions and $1000-5000 \mathrm{~cm}^{-3}$ immediately downwind of continental pollution sources. While $\mathrm{CN}$ concentrations in remote marine regions are broadly in agreement with observations, those in polluted regions are lower than suggested by observations. There are several possible explanations for this discrepancy, including the neglect of primary $\mathrm{CN}$ sources such as carbonaceous aerosol or power plant sulfate and the absence of aerosol nucleation events in the model's boundary layer, which are frequently observed (Kulmala et al., 2004). The effect of primary sulfate on continental CN is examined in Spracklen et al. (2005) and in Adams and Seinfeld (2003).

In a model without significant boundary layer aerosol formation, the UT and FT are the dominant source regions for sulfuric acid particles due to the low temperatures there, which accelerate the rate of binary homogeneous nucleation (Kulmala et al., 1998). These new particles grow through coagulation and condensation as they are transported downwards through the FT and provide a source of particles up to $100 \mathrm{~nm}$ dry diameter above the MBL. The FT particle size distribution is monomodal, while in the MBL the model simulates the typical trimodal distribution with Aitken, accumulation and coarse modes occurring at approximately the correct sizes and number concentrations. The model supports the hypothesis that MBL particle number is sustained by entraining particles which have nucleated in the FT. The contribution of entrained FT sulfate particles to the total $\mathrm{CCN}$ concentration in the MBL varies between about $90 \%$ 
in tropical regions (as a monthly mean) to as little as $25 \%$ at mid-latitudes.

The contribution of anthropogenic sulfur to $\mathrm{CN}$ and $\mathrm{CCN}$ concentrations has been estimated by comparing two runs of the model, one without and one with anthropogenic emissions. The emissions used in the model were such that natural emissions comprised $27 \%$ of the total. The pre-industrial global mean surface $\mathrm{CN}$ concentration was at least $60 \%$ of that in the anthropogenic run, suggesting that natural emissions may contribute disproportionately to the total $\mathrm{CN}$ concentration. The $\mathrm{CCN}$ concentration in the pre-industrial run was $40 \%$ of the anthropogenic run. The relative contribution of natural and anthropogenic emissions to $\mathrm{CN}$ will change when other $\mathrm{CN}$ sources are included in the model.

Acknowledgements. The authors would like to thank F. O'Connor for providing the TOMCAT oxidant fields. Comments from the anonymous reviewer are gratefully acknowledged. DVS was supported by a NERC Universities Global Atmospheric Modelling Programme studentship, KJP by a NERC studentship, and GWM by a NERC Centres for Atmospheric Science grant F14/G6/111.

Edited by: A. Nenes

\section{References}

Abdul-Razzak, H. and Ghan, S.: A parameterisation of aerosol activation: 3. Sectional representation., J. Geophys. Res.-Atmos., 107, 4026, doi:10.1029/2001JD000 483, 2002.

Adams, P. and Seinfeld, J.: Predicting global aerosol size distributions in general circulation models, J. Geophys. Res.-Atmos., 107, 4370, doi:10.1029/2001JD001 010, 2002.

Adams, P. and Seinfeld, J.: Disproportionate impact of particulate emissions on global cloud condensation nuclei concentrations, Geophys. Res. Lett., 30, 43-46, 2003.

Andreae, M., Elbert, W., and de Mora, S.: Biogenic sulfur emissions and aerosols over the tropical South Atlantic 3. Atmospheric dimethylsulfide, aerosols and cloud condensation nuclei, J. Geophys. Res.-Atmos., 100, 11 335-11 356, 1995.

Andreae, T., Andreae, M., and Schebeske, G.: Biogenic sulfur emissions and aerosols over the tropical South Atlantic. 1. Dimethylsulfide in seawater and in the atmospheric boundary layer, J. Geophys. Res.-Atmos., 99, 22 819-22 829, 1994.

Andres, R. and Kasgnoc, A.: A time-averaged inventory of subaerial volcanic sulfur emissions, J. Geophys. Res.-Atmos., 103, 25 251-25 261, 1998.

Andronache, C.: Estimated variability of below-cloud aerosol removal by rainfall for observed aerosol size distributions, Atmos. Chem. Phys., 3, 131-143, 2003,

SRef-ID: 1680-7324/acp/2003-3-131.

Atkinson, R., Baulch, D., Cox, A., Hampson Jr., R., Derr, J., and Troe, J.: Evaluated kinetics and photochemical data for atmospheric chemistry: Supplement III, J. Phys. Chem. Ref. Data, 88, 881-1097, 1989.

Ayers, G., Ivey, J., and Gillett, R.: Coherence between seasonal cycles of dimethylsulfide, methanesulfonate, and sulfate in marine air, Nature, 349, 404-406, 1991.
Barrie, L. and Bottenheim, J.: Pollution in the arctic atmosphere, chap. Sulphur and Nitrogen Pollution in the Arctic Atmosphere, pp. 151-181, Elsevier, New York, 1990.

Barth, M., Rasch, P., Kiehl, J., Benkovitz, C., and Schwartz, S.: Sulfur chemistry in the National Center for Atmospheric Research Community Climate Model: Description, evaluation, features, and sensitivity to aqueous chemistry, J. Geophys. Res.-Atmos., 105, 1387-1415, 2000.

Bates, T., Lamb, B., Guenther, A., Dignon, J., and Stoiber, R.: Sulfur emissions to the atmosphere from natural sources, J. Atmos. Chem., 14, 315-357, 1992.

Beard, K. V. and Grover, S. N.: Numerical collision efficiencies for small raindrops colliding with micron size particles, J. Atmos. Sci., 31, 543-550, 1974.

Benkovitz, C., Scholtz, M., Pacyna, J., Tarrasón, L., Dignon, J., Voldner, E., Spiro, P., Logan, J., and Graedel, T.: Global gridded inventories of anthropogenic emissions of sulfur and nitrogen, J. Geophys. Res.-Atmos., 101, 29 239-29 253, 1996.

Berglen, T., Berntsen, T., Isaksen, I., and Sundet, J.: A global model of the coupled sulfur/oxidant chemistry in the troposphere: The sulfur cycle, J. Geophys. Res.-Atmos., 109, D19310, doi:1029/2003JD003 948, 2004.

Berresheim, H., Andreae, M., Ayers, G., Gillett, R., Merrill, J., Davis, V., and Chameides, W.: Airborne Measurements of Dimethylsulfide, Sulfur Dioxide, and Aerosol Ions over the Southern Ocean South of Australia, J. Atmos. Chem., 10, 341370, 1990.

Binkowski, F. and Rosell, S.: Models-3 Community Multiscale Air Quality (CMAQ) model aerosol component 1. Model description, J. Geophys. Res.-Atmos., 108, 4183, doi:10.1029/2001/JD00 140, 2003.

Birmili, W., Wiedensohler, A., Heintzenberg, J., and Lehmann, K.: Atmospheric particle number size distribution in central Europe: Statistical relations to air masses and meteorology, J. Geophys. Res.-Atmos., 106, 32 005-32 018, 2001.

Blanchard, D. and Cipriano, R.: Biological regulation of climate, Nature, 330, 526, 1987.

Boucher, O. and Anderson, T.: General circulation model assessment to the sensitivity of direct climate forcing by anthropogenic sulfate aerosols to aerosol size and chemistry, J. Geophys. Res.Atmos., 100, 26 117-26 134, 1995.

Boucher, O. and Lohmann, U.: The sulfate-CCN-cloud albedo effect: A sensitivity study with two general circulation models, Tellus, Ser. B, 47, 281-300, 1995.

Carver, G., Brown, P., and Wild, O.: The ASAD atmsopheric chemistry integration package and chemical reaction database, Computer Physics Communications, 105, 197-215, 1997.

Chin, M. and Jacob, D.: Anthropogenic and natural contributions to tropospheric sulfate, J. Geophys. Res.-Atmos., 101, 18691 $18699,1996$.

Chin, M., Jacob, D., Gardner, G., Foreman-Fowler, M., Spiro, P., and Savoie, D.: A global three-dimensional model of tropospheric sulfate, J. Geophys. Res.-Atmos., 101, 18 667-18690, 1996.

Chin, M., Rood, R., Lin, S.-J., Müller, J.-F., and Thompson, A.: Atmospheric sulfur cycle simulated in the global model GOCART: Model description and global properties, J. Geophys. Res.-Atmos., 105, 24 671-24 687, 2000. 
Chuang, C., Penner, J., Taylor, K., Grossmann, A., and Walton, J.: An assessment of the radiative effects of anthropogenic sulfate, J. Geophys. Res.-Atmos., 102, 3761-3778, 1997.

Chuang, C., Penner, J., Prospero, J., Grant, K., Rau, G., and Kawamoto, K.: Cloud susceptibility and the first aerosol indirect forcing: Sensitivity to black carbon and aerosol concentrations, J. Geophys. Res.-Atmos., 107, dio:10.1029/2000JD000 215, 2002.

Chung, S. and Seinfeld, J.: Global distribution and climate forcing of carbonaceous aerosols, J. Geophys. Res.-Atmos., 107, 4407, doi:10.1029/2001JD001 397, 2002.

Clarke, A. and Kapustin, V.: A Pacific Aerosol Survey. Part I: A Decade of Data on Particle Production, Transport, Evolution, and Mixing in the Troposphere, J. Atmos. Sci., 59, 363-382, 2002.

Clarke, A., Ahlquist, N., and Covert, D.: The Pacific marine aerosol: Evidence for natural acid sulfates, J. Geophys. Res.Atmos., 92, 4719-4190, 1987.

Clarke, A., Eisele, F., Kapustin, V., Moore, K., Tanner, D., Mauldin, L., Litchy, M., Lienert, B., Carroll, M., and Albercook, G.: Nucleation in the equatorial free troposphere: Favorable environments during PEM-Tropics, J. Geophys. Res.-Atmos., 104, 5735-5744, 1999.

Cooke, W. and Wilson, J.: A global black carbon aerosol model, J. Geophys. Res.-Atmos., 101, 19395-19409, 1996.

Covert, D., Kapustin, V., Bates, T., and Quinn, P.: Physical properties of marine boundary layer aerosol particles of the mid-Pacific in relation to sources and meteorological transport, J. Geophys. Res.-Atmos., 101, 6919-6930, 1996.

Easter, R., Ghan, S., Zhang, Y., Saylor, R., Chapman, E., Laulainen, N., Abdul-Razzak, H., Leung, L., Bian, X., and Zaveri, R.: MIRAGE: Model description and evaluation of aerosols and trace gases, J. Geophys. Res.-Atmos., 109, D20 210, doi:10.1029/2004JD004 571, 2004.

Emmons, L., Hauglustaine, D., Muller, J.-F., Carroll, M., Brasseur, G., Brunner, D., Staehelin, J., Thouret, V., and Marenco, A.: Data composites of airborne observations of tropospheric ozone and its precursor, J. Geophys. Res.-Atmos., 105, 20 497-20 538, 2000.

Feichter, J., Kjellstrom, E., Rodhe, H., Dentener, F., Lelieveld, J., and Roelofs, G.-J.: Simulation of the tropospheric sulfur cycle in a global climate model, Atmos. Environ., 30, 1693-1707, 1996.

Feichter, J., Lohmann, U., and Schult, I.: The atmospheric sulfur cycle in ECHAM-4 and its impact on short wave radiation, Climate Dynamics, 13, 235-246, 1997.

Fitzgerald, J.: Marine aerosols: A review, Atmos. Environ., 25, 533-545, 1991.

Fuchs, N. and Sutugin, A.: Topics in Current Aerosol Research, chap. Highly dispersed aerosols, Pergemon, pp. 1-60, 1971.

Ghan, S., Easter, R., Hudson, J., and Breon, F.-M.: Evaluation of aerosol indirect radiative forcing in MIRAGE, J. Geophys. Res.Atmos., 106, 5317-5334, 2001.

Giannakopoulos, G., Chipperfield, M., Law, K., and Pyle, J.: Validation and intercomparison of wet and dry deposition schemes using ${ }^{210} \mathrm{~Pb}$ in a global three-dimensional off-line chemical transport model, J. Geophys. Res.-Atmos., 104, 23 761-23 784, 1999.

Gong, S.: A parameterization of sea-salt aerosol source function for sub- and super-micron particles, Global Biogeochemical Cycles, 17, 1097-1103, 2003.
Gong, S. and Barrie, L.: Simulating the impact of sea salt on global nss sulphate aerosols, J. Geophys. Res.-Atmos., 108, 4516-4533, 2003.

Gong, S., Barrie, L., and Blanchet, J.-P.: Modeling sea-salt aerosols in the atmosphere 1. Model Development, J. Geophys. Res.Atmos., 102, 3805-3818, 1997.

Gong, S., Barrie, L., Blanchet, J.-P., von Salzen, K., Lohmann, U., Lesins, G., Spacek, L., Zhang, L., Girard, E., Lin, H., Leaitch, R., Leighton, H., Chylek, P., and Huang, P.: Canadian Aerosol Module: A size-segregated simulation of atmospheric aerosol processes for climate and air quality models 1. Module development, J. Geophys. Res.-Atmos., 108, 4007, doi:10.1029/2001JD002 002, 2003.

Heintzenberg, J. and Larssen, S.: $\mathrm{SO}_{2}$ and $\mathrm{SO}_{4}$ in the arctic: interpretation of observations at three Norwegian arctic-subarctic stations, Tellus, Ser. B, 35B, 255-265, 1983.

Heintzenberg, J., Covert, D., and Van Dingenen, R.: Size distribution and chemical composition of marine aerosols: a compilation and review, Tellus, Ser. B, 52B, 1104-1122, 2000.

Holtslag, A. and Boville, B.: Local versus nonlocal boundary layer diffusion in a globl climate model, J. Clim., 6, 1825-1842, 1993.

Houghton, J., Ding, Y., Griggs, D., Noguer, M., van der Linden, P., Xiaosu, D., Maskell, K., and Johnson, C. (Eds.), Intergovernmental Panel on Climate Change, Climate Change 2001: The Scientific Basis, Cambridge University Press, New York, 2001.

Iversen, T. and Seland, O.: A scheme for process-tagged $\mathrm{SO}_{4}$ and BC aerosols in NCAR CCM3: Validation and sensitivty to cloud processes, J. Geophys. Res.-Atmos., 107, 4751, doi:10.1029/2001JD000 885, 2002.

Jacobson, M.: Development and Application of a new air pollution modeling system. Part II: Aerosol module structure and design, Atmos. Environ., 31A, 131-144, 1997a.

Jacobson, M.: Numerical techniques to solve condensational and dissolutional growth equations when growth is coupled to reversible aqueous reactions, Aerosol Sci. Technol., 27, 491-498, $1997 b$.

Jacobson, M.: GATOR-GCMM: A global- through urban -scale air pollution and weather forecast model 1. Model design and treatment of subgrid soil, vegetation, roads, rooftops, water, sea ice, and snow, J. Geophys. Res.-Atmos., 106, 5385-5401, 2001a.

Jacobson, M.: Global direct radiative forcing due to multicomponent natural and anthropogenic forcing, J. Geophys. Res.Atmos., 106, 1551-1568, 2001b.

Jacobson, M., Turco, R., Jensen, E., and Toon, O.: Modeling coagulation among particles of different composition and size, Atmos. Environ., 28A, 1327-1338, 1994.

Jones, A., Roberts, D., and Slingo, A.: A climate model study of indirect radiative forcing by anthropogenic sulfate aerosols, Nature, 370, 450-453, 1994.

Jones, A., Roberts, D., Woodage, M., and Johnson, C.: Indirect sulphate aerosol forcing in a climate model with an interactive sulphur cycle, J. Geophys. Res.-Atmos., 106, 20 293-20 310, 2001.

Jourdain, B. and Legrand, M.: Seasonal variations of atmospheric dimethylsulfide, dimethylsulfoxide, sulfur dioxide, methanesulfonate, and non-sea-salt sulfate aerosols at Dumont d'Urville (coastal Antartctica) (December 1998 to July 1999), J. Geophys. Res.-Atmos., 106, 14 391-14 408, 2001. 
Kanakidou, M., Tsigaridis, K., Dentener, F., and Crutzen, P.: Human-activity-enhanced formation of organic aerosols by biogenic hydrocarbon oxidation, J. Geophys. Res.-Atmos., 105, 9243-9254, 2000.

Kasibhatla, P., Chameides, W., and St. John, J.: A threedimensional global model investigation of seasonal variations in the atmospheric burden of antropogenic aerosols, J. Geophys. Res.-Atmos., 102, 3737-3759, 1997.

Kettle, A., Andreae, M., Amouroux, D., Andreae, T., Bates, T., Berresheim, H., Bingemer, H., Boniforti, R., Curran, M., DiTullio, G., Helas, G., Jones, G., Keller, M., Kiene, R., Leck, C., Levasseur, M., Malin, G., Maspero, M., Matrai, P., McTaggart, A., Mihalopoulos, N., Nguyen, B., Novo, A., Putaud, J., Rapsomanikis, S., Roberts, G., Schebeske, G., Sharma, S., Simö, R., Staubes, R., Turner, S., and Uher, G.: A global database of sea surface dimethylsulfide (DMS) measurements and a procedure to predict sea surface DMS as a function of latitude, longitude and month, Global Biogeochemical Cycles, 13, 399-444, 1999.

Kiehl, J. and Briegleb, B.: The relative roles of sulfate aerosols and greenhouse gases in climate forcing, Science, 260, 311-314, 1993.

Kiehl, J., Schneider, T., Rasch, P., Barth, M., and Wong, J.: Radiative forcing due to sulfate aerosols from simulations with the National Center for Atmospheric Research Community Climate Model, Version 3, J. Geophys. Res.-Atmos., 105, 1441-1457, 2000.

Kjellstrom, E.: A three-dimensional model study of carbonyl sulfide in the troposphere and lower stratosphere, J. Atmos. Chem., 29, 151-177, 1998.

Koch, D., Jacob, D., Tegen, I., Rind, D., and Chin, M.: Tropospheric sulfur simulation and sulfate direct radiative forcing in the Goddard Institute for Space Studies general circulation model, J. Geophys. Res.-Atmos., 104, 23 799-23 822, 1999.

Korhonen, H., Lehtinen, K., Pirjola, L., Napari, I., Vehkamäki, H., Noppel, M., and Kulmala, M.: Simulation of atmospehric nucleation mode: A comparison of nucleation models and size distribution representations, J. Geophys. Res.-Atmos., 108, 44714479, 2003.

Kulmala, M., Laaksonen, A., and Pirjola, L.: Parameterizations for sulfuric acid/water nucleation rates, J. Geophys. Res.-Atmos., 103, 8301-8307, 1998.

Kulmala, M., Vehkamäki, H., Petajda, T., Dal Maso, M., Lauri, A., Kerminen, V., Birmili, W., and McMurry, P.: Formation and growth rates of ultrafine atmospheric particles: a review of observations, J. Aerosol Sci., 35, 143-176, 2004.

Laj, P., Fuzzi, S., Facchini, M., Orsi, G., Berner, A., Kruisz, C., Wobrock, W., Hallberg, A., Bower, K., Gallagher, M., Beswick, K., Colvile, R., Choularton, T., Nason, P., and Jones, B.: Experimental evidence for in-cloud production of aerosol sulphate, Atmos. Environ., 31, 2503-2514, 1997.

Langner, J. and Rodhe, H.: A Global Three-Dimensional Model of the Troposheric Sulfur Cycle, J. Atmos. Chem., 13, 225-263, 1991.

Lelieveld, J., Roelofs, G.-J., Ganzeveld, L., Feichter, J., and Rodhe, H.: Terrestrial sources and distribution of atmospheric sulfur, Philos. Trans. R. Soc. Lond. B, 352, 149-158, 1997.

Liss, P. and Merlivat, L.: The Role of Air-Sea Exchange in Geochemical Cycling, chap. Air-sea gas exchange rates: Introduction and synthesis, pp. 113-127, D. Reidel, Norwell, Mass., 1986.
Mäkelä, J., Koponen, I., Aalto, P., and Kulmala, M.: One-year data of submicron size modes of troposheric background aerosol in southern Finland, J. Aerosol Sci., 31, 595-611, 2000.

McGraw, R.: Description of aerosol dynamics by the quadrature method of moments, Aerosol Sci. Technol., 27, 255-265, 1997.

McGraw, R. and Wright, D.: Chemically resolved aerosol dynamics for internal mixtures by the quadrature method of moments, J. Aerosol Sci., 34, 189-209, 2003.

Menon, S., DelGenio, A., Koch, D., and Tselioudis, G.: GCM Simulations of the Aerosol Indirect Effect: Sensitivity to Cloud Parametrization and Aerosol Burden, J. Atmos. Sci., 59, 692713, 2002.

Monahan, E., Spiel, D., and Davidson, K.: Oceanic Whitecaps, chap. A model of marine aerosol generation via whitecaps and wave disruption, pp. 167-174, D. Reidel, Norwell, Mass., 1986.

Nenes, A. and Seinfeld, J.: Parameterisation of cloud droplet formation in global climate models, J. Geophys. Res.-Atmos., 108, doi:10.1029/2002JD002 911, 2003.

Nguyen, B., Mihalopoulos, N., Putaud, J., Gaudry, A., Gallet, L., Keene, W., and Galloway, J.: Covariations in oceanic dimethyl sulfide, its oxidation products and rain acidity at Amsterdam Island in the southern Indian Ocean, J. Atmos. Chem., 15, 39-53, 1992.

O'Dowd, C., Lowe, J., Smith, M., and Kaye, A.: The relative importance of non-sea-salt sulphate and sea-salt aerosol to the marine cloud condensation nuclei population: An improved multicomponent aerosol-cloud droplet parametrization, Q. J. R. Meteorol. Soc., 125, 1295-1313, 1999.

Pandis, S., Wexler, A., and Seinfeld, J.: Dynamics of Tropospheric Aerosols, J. Phys. Chem., 99, 9646-9659, 1995.

Pham, M., Müller, J., Brasseur, G., Granier, C., and Mégie, G.: A three-dimensional study of tropospheric sulfur cycle, J. Geophys. Res.-Atmos., 100, 26 061-26 092, 1995.

Prather, M.: Numerical Advection by Conservation of SecondOrder Moments, J. Geophys. Res.-Atmos., 91, 6671-6681, 1986.

Prinn, R., Huang, J., Weiss, R., Cunnold, D., Fraser, P., Simmonds, P., McCulloch, A., Harth, C., Salameh, P., O’Doherty, S., Wang, R., Porter, L., and Miller, B.: Evidence for substantial variations of atmospheric hydroxyl radicals in the past two decades, Science, 292, 1882-1888, 2001.

Quinn, P., Marshall, S., Bates, T., Covert, D., and Kapustin, V.: Comparison of measured and calculated aerosol properties relevant to the direct radiative forcing of tropospheric sulfate on climate, J. Geophys. Res.-Atmos., 100, 8977-8991, 1995.

Raes, F., Van Dingenen, R., Vignati, E., Wilson, J., Putaud, J.-P., Seinfeld, J., and Adams, P.: Formation and cycling of aerosols in the global troposphere, Atmos. Environ., 34, 4215-4240, 2000.

Ramanathan, V., Crutzen, P., Kiehl, J., and Rosenfeld, D.: Aerosols, climate, and the hydrological cycle, Science, 294, 2119-2124, 2001.

Rasch, P., Barth, M., Kiehl, J., Schwartz, S., and Benkovitz, C.: A description of the global sulfur cycle and its controlling processes in the National Center for Atmospheric Research Community Climate Model, Version 3, J. Geophys. Res.-Atmos., 105, 1367-1385, 2000.

Restad, K., Isaksen, I., and Bernsten, T.: Global distribution of sulfate in the troposphere. A three-dimensional model study, Atmos. Environ., 32, 3593-3609, 1998. 
Roelofs, G.-J., Lelieveld, J., and Ganzeveld, L.: Simulation of global sulfate distribution and the influence on effective cloud drop radii with a coupled photochemistry-sulfur cycle model, Tellus, Ser. B, 50, 224-242, 1998.

Rossow, W. and Schiffer, R.: Advances in Understanding Clouds From ISCCP, Bulletin of the American Meteorological Society, 80, 2261-2287, 1999.

Schaug, J., Hansen, J., Nodop, K., Ottar, B., and Pacyna, J.: Summary report from the chemical co-ordinating center for the third phase of EMEP, Tech. Rep. EMEP/CC Rep. 3/87, Norw. Inst. for Air Res., 1987.

Schulz, M., Balkanski, Y., Guelle, W., and Dulac, F.: Role of aerosol size distribution and source location in a threedimensional simulation of Saharan dust episode tested against satellite-derived optical thickness, J. Geophys. Res.-Atmos., 103, 10 579-10 592, 1998.

Sekhon, R. and Srivastava, R.: Doppler observations of drop size distributions in a thunderstorm, J. Atmos. Sci., 28, 983-994, 1971.

Shaw, R. and Paur, R.: Measurements of sulfur in gases and particles during sixteen months in the Ohio River Valley, Atmos. Environ., 17, 1431-1438, 1983.

Sheridan, P., Delene, D., and Ogren, J.: Four years of continuous surface aerosol measurements from the Department of Energy's Atmospheric Radiation Measurement Program Southern Great Plains Cloud and Radiation Testbed site, J. Geophys. Res.Atmos., 106, 20 735-20 747, 2001.

Slinn, S. and Slinn, W.: Atmospheric Pollutants in natural waters, chap. Modeling of atmospheric particulate deposition to natural water, pp. 23-53, Ann. Arbour. Sci., 1981.

Slinn, W.: Atmospheric Sciences and Power Production, chap. Precipitation Scavenging, US Department of Energy, 1983.

Spracklen, D., Pringle, K., Carslaw, K., Chipperfield, M., and Mann, G.: A global off-line model of size resolved aerosol processes; II. Importance of uncertainties in microphysical processes, Atmospheric Chemistry and Physics Discussions, 5, 3437-3489, 2005,

\section{SRef-ID: 1680-7375/acpd/2005-5-3437.}

Stockwell, D. and Chipperfield, M.: A tropospheric chemicaltransport model: Development and validation of the model transport schemes, Q. J. R. Meteorol. Soc., 125, 1747-1783, 1999.

Stolzenburg, M. and McMurry, P.: An ultrafine aerosol condensation nucleus counter, Aerosol Sci. Tech., 14, 48-65, 1991.

Tegen, I. and Fung, I.: Modeling mineral dust in the atmosphere: Sources, transport and optical thickness, J. Geophys. Res.-Atmos., 99, 22 897-22 914, 1994.

Tegen, I., Koch, D., Lacis, A., and Sato, M.: Trends in tropospheric aerosol loads and corresponding impact on direct radiative forcing between 1950 and 1990: A model study, J. Geophys. Res.Atmos., 105, 26971-26989, 2000.
Thornton, D., Bandy, A., Beltz, N., Driedger, A., and Ferek, R.: Advection of sulfur dioxide over the western Atlantic Ocean during CITE-3, J. Geophys. Res.-Atmos., 98, 23 459-23 467, 1993.

Tiedtke, M.: A comprehensive mass flux scheme for cumulus parameterization in large scale models, Mon. Wea. Review, 117, 1779-1800, 1989.

Van Dingenen, R., Raes, F., and Jensen, N.: Evidence for anthropogenic impact on number concentration and sulfate content of cloud-processed aerosol particles over the North Atlantic, J. Geophys. Res.-Atmos., 100, 21 057-21 067, 1995.

Vignati, E., Wilson, J., and Stier, P.: M7: An efficient size-resolved aerosol microphysics module for large-scale aerosol transport models, J. Geophys. Res.-Atmos., 109, doi:10.1029/2003JD004 485, 2004.

von Salzen, K., Leighton, H., Ariya, P., Barrie, L., Gong, S., Blanchet, J.-P., Spacek, L., Lohmann, U., and Kleinman, L.: Sensitivity of sulphate aerosol size distributions and $\mathrm{CCN}$ concentrations over North America to $\mathrm{SO}_{\mathrm{x}}$ emissions and $\mathrm{H}_{2} \mathrm{O}_{2}$ concentrations, J. Geophys. Res.-Atmos., 105, 9741-9765, 2000.

Whitby, E. and McMurry, P.: Modal aerosol dynamics modeling, Aerosol Sci. Technol., 27, 673-688, 1997.

Whitby, K.: The physical characteristics of sulfur aerosols, Atmos. Environ., 12, 135-159, 1978.

Wilson, J., Cuvelier, C., and Raes, F.: A modeling study of global mixed aerosol fields, J. Geophys. Res.-Atmos., 106, 34081 $34108,2001$.

Wright, D. and Kasibhatla, P.: Description and evaluation of a six-moment aerosol microphysical module for use in atmospheric chemical transport models, J. Geophys. Res.-Atmos., 106, 20 275-20291, 2001.

Wright, D., McGraw, R., Benkowitz, C., and Schwartz, S.: Sixmoment representation of multiple aerosol populations in a sub-hemispheric chemical transformation model, Geophys. Res. Lett., 27, 967-970, 2000.

Wright, D., Yu, S., Kasibhatla, P., McGraw, R., Schwartz, S., Saxena, V., and Yue, G.: Retrieval of aerosol properties from moments of the particle size distribution for kernels involving the step function: cloud droplet activation, J. Aerosol Sci., 33, 319337, 2002.

Yoon, Y. and Brimblecombe, P.: Modelling the contribution of sea salt and dimethyl sulfide derived aerosol to marine CCN, Atmos. Chem. Phys., 2, 17-30, 2002,

SRef-ID: 1680-7324/acp/2002-2-17.

Yu, S., Kasibhatla, P., Wright, D., Schwartz, S., McGraw, R., and Deng, A.: Moment-based simulation of microphysical properties of sulfate aerosols in the eastern United States: Model description, evaluation, and regional analysis, J. Geophys. Res.-Atmos., 108, 4353, doi:10.1029/2002JD00289, 2003.

Zhang, L., Gong, S., Padro, J., and Barrie, L.: A size-segregated particle dry deposition scheme for an atmospheric aerosol module, Atmos. Environ., 35, 549-560, 2001. 